- Estudi -

\title{
MARCO JURÍDICO DE LA EXTRACCIÓN DE HIDROCARBUROS MEDIANTE FRACTURA HIDRÁULICA (FRACKING)
}

\author{
ELISA MOREu CARBONELL ${ }^{1}$ \\ Profesora titular de Derecho Administrativo \\ Universidad de Zaragoza \\ emoreu@unizar.es
}

Recibido: 28 de septiembre de 2012 / Aceptado: 29 de octubre 2012

RESUMEN: La extracción de hidrocarburos no convencionales mediante fractura hidráulica, técnica conocida como fracking, ha experimentado una gran difusión en el mercado energético, convirtiéndose en una fuente de abastecimiento de gran potencial para reducir la dependencia energética del exterior no solo en EE. UU., sino también en los países europeos. Este trabajo asume como objetivo definir el marco jurídico europeo y nacional - del fracking, denunciar las dificultades de inadaptación de dicho marco jurídico para afrontar los requerimientos ambientales que implica la utilización de esta técnica y ofrecer propuestas de regulación. El estudio dedica una atención especial al derecho minero francés, que mediante la Ley 2011-835 ha prohibido en todo el territorio francés la extracción de hidrocarburos líquidos o gaseosos mediante fractura hidráulica.

RESUM: L'extracció d'hidrocarburs no convencionals per fractura hidràulica, denominat fracking, ha experimentat una gran difusió en el mercat de l'energia, i s'ha convertit en una font de gran potencial per reduir la dependència energètica de l'exterior, no només en els EUA sinó també a Europa. Aquest treball defineix el marc jurídic —europeu i nacional— del fracking, denuncia les dificultats d'inadequació del marc jurídic per abordar els requisits ambientals que implica l'ús d'aquesta tècnica $\mathrm{i}$

\footnotetext{
${ }^{1}$ Agradezco a mi colega Alba Nogueira, siempre sensible a los problemas ambientales, su generosidad al proponerme tratar el tema y animarme a escribir estas páginas para esta revista.
} 
ofereix propostes de regulació. L'estudi posa especial atenció al Dret miner francès, que mitjançant la Llei 2011-835 ha prohibit al llarg del territori francès l'extracció d'hidrocarburs líquids o gasosos utilitzant la tècnica de la fractura hidràulica.

ABSTRACT: The exploration/prospection for unconventional hydrocarbons by hydraulic fracturing (fracking) has a great diffusion in the energy market. It has become a source of great potential to reduce energy dependence on abroad in the USA and Europe. As the use of hydraulic fracturing has grown, so have concerns about its environmental and public health impacts. This study defines the legal framework (European and national), denounces the inadequacy to deal with the environmental requirements and offers proposals for regulation. The study pays special attention to the French Prohibition Act 2011-835. This law has led to the announced abrogation of authorisations that were granted legally at the first place.

PALABRAS CLAVE: Derecho energético y minero - hidrocarburos no convencionales - fractura hidráulica — permisos de investigación — evaluación de impacto ambiental.

PARAULES CLAU: Dret energètic i miner - Hidrocarburs no convencionals Fractura hidràulica - Permisos d'investigació - Avaluació d'impacte ambiental.

KEYWORDS: Energy and mining law — unconventional hydrocarbons - hydraulic fracturing - exploration authorisation - environmental impact assessment. 
Sumario: I. Introducción. La edad de oro de los hidrocarburos no convencionales. 1. ¿Una nueva burbuja económica? 2. Riesgos potenciales de contaminación del proceso de fractura hidráulica. II. Marco jurídico de la fractura hidráulica en la Unión Europea. 1. El creciente interés de las instituciones comunitarias. 2. Lagunas del marco normativo europeo. III. La prohibición legal de la fractura hidráulica en Francia. 1. Alcance y justificación de la prohibición legal. 2. Insuficiencias del nuevo Code Minier francés. IV. La fractura hidráulica en España. 1. Los proyectos en marcha. 2. Ambigüedades de la legislación española vigente. V. Conclusiones. VI. Bibliografía.

\section{INTRODUCCIÓN. LA EDAD DE ORO DE LOS HIDROCARBUROS NO CONVENCIONALES}

Hasta hace muy poco tiempo la explotación de hidrocarburos (líquidos o gaseosos) mediante fractura hidráulica era una actividad industrial relativamente desconocida entre nosotros, al menos en el espacio europeo, y no solo desde la perspectiva jurídica que orienta la presente investigación. Despacio, sin hacer mucho ruido, los medios de comunicación recogen noticias relacionadas con la puesta en marcha de proyectos de exploración de recursos no convencionales; organismos e instituciones europeos elaboran informes al respecto; y se publican estudios sobre su repercusión económica y ambiental. El impacto mediático del documental Gasland, del realizador norteamericano Josh Fox ${ }^{2}$, unido a un incremento pasmoso de los permisos solicitados y concedidos en el territorio europeo, están empezando a focalizar la atención sobre estos hidrocarburos "no convencionales" y sus técnicas de extracción. Para ALONSO SUÁREZ y MINGO GONZÁLEZ, estamos ante una "revolución silenciosa", si bien Benavides Salas considera "harto sorprendente" que las nuevas tecnologías para la explotación de yacimientos no convencionales apenas hayan provocado resistencias ni generado críticas, cuando proyectos energéticos o de infraestructuras menos dañinos han dado lugar a dramáticas reacciones en el pasado ${ }^{3}$.

A denunciar estas lagunas o incongruencias, definir el marco jurídico aplicable y ofrecer propuestas de regulación se dedican las páginas que siguen.

\footnotetext{
${ }^{2}$ El documental Gasland, ganador del Premio Especial del Jurado al Mejor Documental Norteamericano en el festival de Sundance 2010, recoge los testimonios y las reacciones de ciudadanos afectados por las explotaciones de gas no convencional a través de un viaje por 24 estados americanos, desde Pennsylvania hasta Utah, de un extremo al otro de los Estados Unidos.

${ }^{3}$ ALONSO SUÁREZ y MINGO GONZÁLEZ, "La expansión de la producción de gas de yacimientos no convencionales (esquistos, capas de carbón y arenas compactas). Una revolución silenciosa", Cuadernos de Energía, núm. 28, 2010, p. 5, y BENAVIDES SALAS, "La energía en su laberinto", Cuadernos de Energía, núm. 35, 2012, p. 14.
} 
Los recursos no convencionales son hidrocarburos (petróleo y gas) que, por estar atrapados en rocas madre poco permeables o por tratarse de fluidos de muy alta viscosidad, no se pueden extraer sin el empleo de una tecnología especial, distinta de las técnicas clásicas utilizadas durante el auge de los hidrocarburos en el siglo XX. Según la definición del Instituto Geológico y Minero de España (IGME), el hidrocarburo no convencional "no puede ser producido con rentabilidad a menos que el yacimiento sea estimulado por fractura hidráulica masiva o recurriendo a la perforación de multilaterales desde un pozo principal"4. En la actual coyuntura económica representan una atractiva fuente de recursos en yacimientos que se daban por agotados y están generando enormes expectativas de inversión económica, especialmente en el sector gasístico. Hasta tal punto que la extracción de gas no convencional supone ya el 15\% de la producción mundial de gas, aunque sus reservas constituyen tan solo el 4\% del total.

El término hidrocarburo no convencional es poco afortunado, ya que "no convencional" no es un rasgo intrínseco del recurso (tanto el gas como el petróleo obtenidos son, composicional y genéticamente, exactamente iguales), sino de las características geológicas del yacimiento donde se ubica, de las condiciones en las que están atrapados en la roca madre y de la técnica empleada para su extracción. Como digo, la explotación de un yacimiento no convencional exige la estimulación de la roca madre donde se encuentra atrapado el recurso, y para eso se utiliza una técnica de estimulación conocida como fractura hidráulica (del inglés hydraulic fracturing o fracking) que — simplificadamente - consiste en inyectar a muy alta presión millones de litros de agua mezclados con productos químicos y arena en los yacimientos del subsuelo, a unas profundidades en torno a los dos kilómetros, para conseguir que la roca se rompa y libere el recurso a través de una serie de pozos (cientos de ellos) excavados en la superficie.

4 Voz gas natural del Panorama Minero que elabora el IGME, disponible en $<$ www.igme.es/internet/PanoramaMinero/PMLin.htm>. La denominación de hidrocarburo "no convencional" comprende recursos muy distintos tanto en estado líquido como gaseoso, entre otros: 1) los esquistos petrolíferos y gasísticos, encerrados en la roca madre, también denominados petróleo o gas de esquisto (shale oil y shale gas, en inglés); 2) las arenas compactas petrolíferas y gasísticas (tight sand y tight oil); 3) el gas de carbón, impregnado en vetas de carbón (coal bed methane o CBM); 4) los hidratos de gas (gas hydrates); y 5) el petróleo extrapesado que, debido a su alta viscosidad y densidad, no fluye en condiciones normales (heavy oil). Véase también MARZO, "Recursos convencionales y no convencionales de petróleo y gas”, Enseñanza de las Ciencias de la Tierra, núm. 16.3, 2008, p. 218. La mayoría de los trabajos sobre fractura hidráulica suelen limitarse, con cierta imprecisión, al gas no convencional; pero el término de hidrocarburo o recurso "no convencional" no se limita al shale gas. 
Desde hace décadas se sabe que existen reservas de este tipo en muchas zonas donde se explotaban yacimientos convencionales de hidrocarburos. Tampoco la fractura hidráulica es una técnica nueva, pues se utiliza para mejorar la productividad de los pozos convencionales no solo en EE. UU., sino también en Europa. Pero los últimos avances tecnológicos y la superación de desafíos técnicos que hasta hace poco parecían insalvables han incrementado notablemente su efectividad y productividad. Eso explicaría, en expresión de la Agencia Internacional de la Energía, esta "revolución" o "edad de oro" de los recursos no convencionales que se extiende por todo el planeta con inusitada rapidez ${ }^{5}$. Con todo, dichos recursos son más costosos de producir, presentan un mayor impacto ambiental y, además, su explotación implica un balance energético considerablemente menor que el de los recursos convencionales ${ }^{6}$.

\section{1. ¿Una nueva burbuja económica?}

Cualquier análisis de los recursos no convencionales debe situarse en un contexto económico muy particular de crisis energética y afán por reducir la dependencia del exterior tanto en Estados Unidos como en Europa. Esta peculiar coyuntura viene marcada por el precio creciente del petróleo, el irreversible agotamiento de las reservas tradicionales, la preocupación por el abastecimiento de materias primas, la dependencia externa de fuentes de energía y la búsqueda de fuentes alternativas. El gas (y el petróleo) de esquisto se ha convertido así en una novedosa fuente de abastecimiento de gran importancia potencial en toda Europa ${ }^{7}$, si bien el foco de la producción se sitúa en

5 AGENCIA INTERNACIONAL DE LA ENERGÍA, "Golden Rules for a Golden Age of Gas, World Energy Outlook, Special Report on Unconventional Gas”, 2012, p. 15. Recuperado el 9 de julio de 2012 de $<$ www.worldenergyoutlook.org/goldenrules/ - d.en.27023>.

\footnotetext{
${ }^{6}$ MARZO, "Recursos convencionales y no convencionales...” cit., p. 222.

${ }^{7}$ Según datos de la AGENCIA INTERNACIONAL DE LA ENERGÍA, “Golden Rules...” cit., p. 120, las reservas europeas se localizarían en tres grandes áreas: (1) este de Dinamarca y sur de Suecia hasta la zona este de Polonia; (2) noroeste del Reino Unido, pasando por los Países Bajos y el noroeste de Alemania hasta el sudoeste de Polonia; y (3) sur de Reino Unido hasta el norte de Francia, Países Bajos, Alemania y Suiza. Francia, Polonia y Estonia cuentan con los principales yacimientos no convencionales de Europa, seguidos de Noruega, Ucrania, Suecia, Dinamarca y Reino Unido. Véase también SCHULZ, HORSFIELD, KAPP, "Shale Gas: eine unkonventionelle Gasressource für den zukünftigen Energiemix in Europa?”, Bergbau. Zeitschrift für Rohstoffgewinnung, Energie, Umwelt, núm. 6, 2011, p. 252.
}

En el año 2009 se creó el consorcio GASH (Gas Shales in Europe, <www.gas-shales.org>), integrado por un conjunto de empresas gasísticas (Repsol entre ellas), con el objetivo de estudiar las reservas europeas y elaborar estudios interdisciplinarios sobre estos recursos. 
EE. UU. ${ }^{8}$. El documento elaborado por la Comisión Europea conocido como "Hoja de Ruta de la Energía para 2050" constata que la explotación de las reservas nativas de gas no convencional "podría suponer un alivio para las preocupaciones sobre la dependencia de las importaciones de gas",9.

Sin embargo, algunas sombras se ciernen sobre esta euforia desmedida. La propia Comisión Europea sospecha que “debido a la fase temprana de exploración no está claro cuándo podrán ser importantes los recursos no convencionales", y que se desconoce "hasta qué punto resultará viable el gas de esquisto bituminoso en Europa"10. Los especialistas alertan sobre una exageración de las expectativas creadas ante estos recursos no convencionales, la magnitud de sus reservas y su capacidad de reducir la dependencia energética ${ }^{11}$. La experiencia de los EE. UU., que es hasta la fecha el principal y casi único productor, hace temer que nos encontremos ante un gigantesco esquema piramidal o una nueva burbuja económica ${ }^{12}$. Las falsas expectativas generadas

${ }^{8}$ El último informe de la ADMINISTRACIÓN DE INFORMACIÓN ENERGÉTICA DE EE. UU., Annual Energy Outlook (AEO2012), DOE/EIA-0383(2012), 2012, pp. 3 y 57 (recuperado el 10 de septiembre de 2012 de <www.eia.gov/forecasts/aeo/>), señala que la producción de gas no convencional supone hoy casi la mitad (49\%) de la producción de gas en los EE. UU., en contraste con el $16 \%$ que suponía a comienzos de la década de 1990. Este incremento ha conseguido que, desde 2009, EE. UU. haya desplazado a Rusia como principal productor de gas natural del mundo.

A pesar de todo, el informe de 2012 aprecia un ligero decrecimiento de la producción de shale gas, ya que "están pendientes de resolver ciertas incertidumbres que rodean a los avances tecnológicos que han hecho de la producción de gas de esquisto una realidad", estimándose el impacto de estas "incertidumbres" entre 0,27 y 0,58 billones de $\mathrm{m}^{3}$ anuales hasta el año 2035. También la estimación de las reservas se ha reducido en un solo año casi a la mitad, de 23,4 billones de $\mathrm{m}^{3}$ en 2011 a 13,6 billones de $\mathrm{m}^{3}$ en 2012 . Dichas "incertidumbres" se explican sobre todo por el impacto que para el sector supondría la confirmación de un impacto ambiental negativo de las explotaciones de gas no convencional, que empieza a tomar fuerza en diversos informes elaborados por la Agencia de Protección Ambiental de EE. UU. (EPA) o por instituciones independientes.

9 COMISIÓN EUROPEA, "Hoja de Ruta de la Energía para 2050", COM(2011) 885 final, de 15 de diciembre de 2011, p. 14.

${ }^{10}$ Ibíd., p. 3.

${ }^{11}$ Al respecto, MOONEY, "Los inconvenientes de la fractura hidráulica", Investigación y Ciencia, núm. 424, 2012, p. 82; CENTRO DE SOLUCIONES DE ENERGÍA DE DELOITTE Y DELOITTE MARKETPOINT LLC, "El impacto económico de las exportaciones de GNL desde EEUU", Cuadernos de Energía, núm. 35, 2012, p. 36; ZITTEL, "Shale Gas. European Perspectives", ponencia de la 10." Convención Anual de la Association for the Study of Peak Oil \& Gas (ASPO), Viena, 2012, p. 24, (recuperado el 23 de julio de 2012 de <www.aspo2012.at/>); y MEARNS, "Unconventional Oil and Gas, a Game Changer?", ponencia de la 10. ${ }^{a}$ Convención Anual de la Association for the Study of Peak Oil \& Gas (ASPO), Viena, 2012, p. 2 (recuperado el 23 de julio de 2012 de <www.aspo2012.at/>), que encabeza su ponencia con una cita del geólogo Colin J. Campbell: "Todos los números se equivocan, eso ya lo sabemos; la pregunta es: ¿hasta qué punto se equivocan?”.

${ }^{12}$ Una investigación periodística del diario The New York Times publicada el 25 junio de 2011 analiza cientos de correos electrónicos y documentos internos desclasificados de la industria del sector (recuperado el 4 de julio de 2012 de <http:/www.nytimes.com/interactive/us/natural-gas-drilling-downdocuments-4.html $>$ ). El informe llega a la conclusión de que las compañías que explotan recursos no 
esconderían una escasa posibilidad de negocio real, que solo resulta rentable en la medida en que crece la cantidad de nuevos inversores, cegados por las promesas de obtener pingües beneficios o, en su caso, como vía indirecta para introducir determinados productos en el mercado como los secretísimos fluidos de fractura necesarios para el fracking ${ }^{13}$. Eso explicaría la optimista tolerancia de los Estados europeos ante los proyectos de gas natural y, desde luego, el incremento del número de permisos solicitados y concedidos. En el contexto de crisis energética al que he hecho referencia, los Gobiernos europeos se esfuerzan por conseguir una opinión pública favorable lanzando globos sonda mediáticos con estimaciones poco fiables sobre la magnitud de las reservas y su importancia para la economía nacional.

\section{Riesgos potenciales de contaminación del proceso de fractura hidráulica}

El punto débil de la extracción no convencional de hidrocarburos es su negativo impacto sobre el medio ambiente y la salud humana. Desde EE. UU., que es el primer país productor del mundo, se oyen numerosas voces de alarma y crece la preocupación por los efectos nocivos del fracking ${ }^{14}$. No podemos pasar por alto que la explotación de gas (y petróleo) de esquisto se ha visto allí extraordinariamente potenciada en los últimos años no solo por la necesidad de retroalimentar la burbuja económica creada a su alrededor, sino, principalmente, porque los Gobiernos norteamericanos han aprobado numerosas excepciones a las leyes ambientales desde el año $2005^{15}$. Además, en el derecho de los EE. UU. no existe la propiedad pública del subsuelo, así que los pozos se instalan sin otro requisito que la autorización del propietario de la superficie a cambio de una renta o compensación. Otra razón más para poner en cuarentena las expectativas

convencionales están sobrevalorando intencionadamente la productividad de los pozos y el tamaño de las reservas. Según el diario estadounidense, el escepticismo que se desprende al leer estos documentos contrasta con el optimismo que la industria expresa en público y que recuerda al contexto de otras burbujas anteriores como la de las empresas puntocom o la del sector inmobiliario.

13 HIDALGO GARCÍA, "Los elementos químicos críticos para las nuevas tecnologías del sector energético", Cuadernos de Energía, núm. 35, 2012, p. 44.

${ }^{14}$ Es muy significativo que la AGENCIA DE PROTECCIÓN AMBIENTAL DE EE. UU. (EPA), "Plan to Study the Potential Impacts of Hydraulic Fracturing on Drinking Water Resources" (EPA/600/R11/122), 2011, p. 14 (recuperado el 3 de julio de 2012 de <www.epa.gov/hfstudy/index.html>), no haya concluido todavía un estudio a gran escala sobre la seguridad del fracking, previsto para el año 2014, y que, sin embargo, haya tolerado que las empresas gasísticas realicen sus perforaciones sin conocer el alcance y el impacto de dichas técnicas.

${ }^{15}$ Son datos de la AGENCIA INTERNACIONAL DE LA ENERGÍA, “Golden Rules...” cit., p. 104. 
generadas por las empresas del sector energético en Europa, donde las exigencias jurídicas y ambientales son —afortunadamente y esperamos que siga siendo asímucho más rigurosas.

¿Cuáles son estas afectaciones ambientales de la fractura hidráulica?

\subsection{Impacto sobre los recursos hidráulicos}

El mayor riesgo de la explotación no convencional es su impacto sobre el agua tanto por los grandes volúmenes de agua consumida durante el proceso de fractura hidráulica como por el riesgo de contaminación de aguas subterráneas y acuíferos, especialmente a nivel de la capa freática ${ }^{16}$. Por lo que respecta a la cantidad de agua utilizada para la fractura hidráulica, oscila entre 9.000 y 20.000 metros cúbicos por cada pozo, teniendo en cuenta que la fase de estimulación dura aproximadamente 40 días y que por cada permiso concedido se perforan varias decenas de pozos. El volumen de agua utilizada no es proporcional a la productividad del yacimiento no convencional y podría causar problemas de sostenibilidad de los recursos hídricos incluso en países de clima templado $^{17}$.

El proceso de extracción tiene, además, dos momentos críticos. El primero durante la fractura en sentido estricto, ya que por efecto de la elevada presión del fluido inyectado

\footnotetext{
${ }^{16}$ Diversas investigaciones realizadas por los científicos OSBORN, VENGOSH, WARNER, JACKSON, "Methane contamination of drinking water accompanying gas-well drilling and hydraulic fracturing", en PNAS, Proceedings of the National Academy of Sciences of the United States of America, vol. 108, núm. $20, \quad 2011$ p p. 8172-8176 (recuperado el 2 de julio de 2012 de <www.pnas.org/cgi/doi/10.1073/pnas.1100682108>), y JACKSON, PEARSON, OSBORN, WARNER, VENGOSH, "Research and Policy Recommendations for Hydraulic Fracturing and Shale-Gas Extraction", Center on Global Change, Duke University, Durham, NC, 2011, de la Duke University de Durham (EE. UU.), concluyen que el $85 \%$ de los pozos de agua analizados en los estados de Pensilvania y Nueva York contienen metano procedente de la explotación de gas no convencional.

Otro informe de la AGENCIA DE PROTECCIÓN AMBIENTAL DE EE. UU. (EPA), "Investigation of Ground Water Contamination near Pavillion, Wyoming" (EPA 600/R-00/000), 2011 (recuperado el 4 de julio de 2012 de <www.epa.gov/hydraulicfracturing/>), aporta evidencias científicas de que la contaminación de las aguas subterráneas está asociada a la fractura hidráulica, confirmadas en los estudios más recientes de WARNER, JACKSON, DARRAH, OSBORN, DOWN, ZHAO, WHITE, VENGOSH, "Geochemical evidence for possible natural migration of Marcellus Formation brine to shallow aquifers in Pennsylvania", PNAS, Proceedings of the National Academy of Sciences of the United States of America, 2012 (recuperado el 24 de julio de 2012 de $<$ www.pnas.org/cgi/doi/10.1073/pnas.1121181109>), y MYERS, "Potential Contaminant Pathways from Hydraulically Fractured Shale to Aquifers", Journal of the National Ground Water Association, 2012, p. 9 (recuperado el 9 de julio de 2012 de $<$ www.ngwa.org $>$ ).

${ }^{17}$ Así lo denuncia GREENPEACE, "Fractura hidráulica para extraer gas natural", 2011. Recuperado el 6 de septiembre de 2012 de <http://www.greenpeace.org/espana/Global/espana/.../Fracking-GP_ESP.pdf $>$.
} 
las grietas en la roca madre pueden abrirse sobre zonas más amplias que las inicialmente proyectadas y filtrarse hacia los acuíferos. El riesgo se incrementa en la medida en que el fluido de fractura contiene aditivos químicos, algunos altamente tóxicos, que se filtran en el agua ${ }^{18}$. El segundo momento crítico se produce cuando una parte del fluido de fractura (entre un 30\% y un $80 \%$ según las estimaciones) retorna hacia la superficie, al final del proceso de fractura, debido a las deficiencias en la cimentación y el aislamiento de los tubos de revestimiento de los pozos de perforación. Dicho fluido residual generado por la fractura hidráulica contiene substancias tóxicas provenientes del subsuelo como metales pesados (arsénico, plomo, cromo, mercurio), substancias radiactivas de origen natural (uranio, radio, radón), bencenos y grandes concentraciones de sales. Una parte del fluido de retorno se reinyecta en el subsuelo, otra se reutiliza para nuevas operaciones y otra, finalmente, se almacena en balsas de evaporación, con el consiguiente peligro de contaminación atmosférica, o se transporta hacia instalaciones de depuración que no suelen estar suficientemente preparadas para tratar este tipo de residuos.

\subsection{Producción de residuos tóxicos}

Como digo, la fractura hidráulica genera residuos altamente tóxicos. No solo el fluido recuperado tras el proceso de fractura, sino también un porcentaje del fluido de fractura que se queda en el subsuelo y no retorna a la superficie.

\subsection{Contaminación atmosférica}

También existe una seria preocupación por los diferentes episodios de contaminación atmosférica provocados por la explotación mediante técnicas no convencionales, ya que entre un $3,6 \%$ y un $8 \%$ del recurso escapa al ambiente a lo largo del proceso, bien cuando emerge el fluido de retorno, bien por fugas accidentales durante la extracción, el transporte, el almacenamiento o la distribución. Se estima que el gas no convencional produce emisiones de gases de efecto invernadero entre un $30 \%$ y un $100 \%$ mayores

\footnotetext{
${ }^{18}$ Según un informe elaborado en abril de 2011 por la Comisión de la Energía y Comercio de la Cámara de Representantes de EE. UU., las compañías del sector utilizan más de 2.500 productos de fractura hidráulica que contienen 750 compuestos químicos, de los cuales 29 se identifican como cancerígenos, presentan riesgos graves para la salud humana y son potenciales contaminantes de la calidad del aire (recuperado el 24 de julio de 2012 de <http://democrats.energycommerce.house.gov/>).
} 
que el carbón ${ }^{19}$. Por esta razón, no debería promocionarse - aunque se hace- como "energía de transición" hacia un modelo energético bajo en emisiones, pues no contribuye a reducir el calentamiento global del planeta y tiene como efecto secundario pernicioso el desvío o retraso en la inversión en otras tecnologías y fuentes de energía alternativas no contaminantes ${ }^{20}$.

Adicionalmente, las poblaciones cercanas a las explotaciones no convencionales sufren el ruido, las vibraciones y los olores propios de las operaciones de perforación, y las molestias provocadas por los miles de viajes que realizan los camiones para transportar los fluidos de fractura, que también suponen una degradación del paisaje. No obstante, estas operaciones duran apenas unas semanas por cada yacimiento, y aproximadamente uno o dos meses después del comienzo de la perforación la mayoría de equipamientos se retiran. Por último, existe un riesgo nada desdeñable de seísmos producidos por el fracking ${ }^{21}$.

\section{MARCO JURÍDICO DE LA FRACTURA HIDRÁULICA EN LA UNIÓN EUROPEA}

El objetivo de este epígrafe es presentar una sinopsis del marco normativo de la UE para la extracción de hidrocarburos no convencionales mediante fractura hidráulica, y averiguar si existen disposiciones comunitarias encaminadas a reducir o evitar los riesgos derivados de estas actividades.

\footnotetext{
${ }^{19}$ El informe elaborado por HOWARTH, SANTORO, INGRAFFEA, "Methane and the greenhouse-gas footprint of natural gas from shale formations", Climatic Change Letters, vol. 106, núm. 4, 2011, p. 679 (recuperado el 3 de julio de 2012 de <www.springerlink.com/content/0165-0009/106/4/>), confirmaría que la técnica del fracking produce gases de efecto invernadero y tiene un gran impacto sobre el cambio climático.

${ }^{20}$ Así parece confirmarlo el estudio de WOOD, GILBERT, SHARMINA, ANDERSON, FOOTITT, GLYNN, NICHOLLS, "Shale gas: a provisional assessment of climate change and environmental impacts", informe del Tyndall Centre for Climate Change Research, 2011, p. 5 (recuperado el 2 de julio de 2012 de <www.tyndall.ac.uk/publications/technical-report/2011/shale-gas-provisional-assessmentclimate-change-and-environmental $>$ ). El Tyndall Centre for Climate Change Research (Centro Tyndall para la Investigación del Cambio Climático) es una organización pluridisciplinaria a la que pertenecen ocho universidades del Reino Unido y que desarrolla propuestas relativas al cambio climático.

${ }^{21}$ BAMBERGER, OSWALD, "Impacts of Gas Drilling on Human and Animal Health", New Solutions. A Journal of Environmental and Occupational Health Policy, vol. 22 núm. 1, 2012, p. 75.
} 


\section{El creciente interés de las instituciones comunitarias}

El fracking $\mathrm{y}$, en general, la explotación de yacimientos no convencionales han empezado a ser objeto de atención por las instituciones de la Unión Europea. La "Hoja de Ruta de la Energía para 2050", elaborada por la Comisión Europea, insiste en la importancia potencial del gas de esquisto y otros recursos no convencionales como nuevas fuentes de abastecimiento en Europa ${ }^{22}$. Hasta la fecha se han elaborado cuatro estudios sobre el impacto ambiental y el marco normativo de la explotación no convencional de hidrocarburos, tres a propuesta del Parlamento Europeo y uno por encargo de la Comisión. Lo curioso es que estos informes llegan a conclusiones muy distintas, incluso contradictorias.

\subsection{Primer informe del Parlamento Europeo}

Haciéndose eco de una creciente inquietud entre la población europea, el Parlamento Europeo encargó al prestigioso Instituto del Clima, Medio Ambiente y Energía de Wuppertal (Wuppertal Institut für Klima, Umwelt und Energie) y al Ludwig-BölkowSystemtechnik el estudio las "Repercusiones de la extracción de gas petróleo de esquisto en el medio ambiente y la salud humana", que fue presentado el 15 junio $2011^{23}$. Este informe defiende la conveniencia de elaborar una directiva (marco) de la Unión Europea que regule las actividades mineras, y critica el retraso en realizar un análisis público, amplio y detallado del marco normativo relativo a la extracción de hidrocarburos no convencionales.

\subsection{Informe de la Comisión Europea}

Le sigue, cronológicamente, el informe encargado por la Comisión Europea al bufete Philippe \& Partners que lleva por título "Final report on unconventional gas in Europe", de fecha 27 de enero de $2012^{24}$. El objetivo principal del estudio es analizar cómo se

\footnotetext{
${ }^{22}$ COMISIÓN EUROPEA, "Hoja de Ruta de la Energía para 2050...” cit., p. 14.

${ }^{23}$ PARLAMENTO EUROPEO, "Repercusiones de la extracción de gas petróleo de esquisto en el medio ambiente y la salud humana" (IP/A/ENVI/ST/2011-07), de 15 junio 2011. Recuperado el 2 de julio de 2012 de $<$ www.europarl.europa.eu/committees/es/studies.html - studies>.

${ }^{24}$ COMISIÓN EUROPEA, "Final report on unconventional gas in Europe", elaborado por Philippe \& Partners, 2012. Recuperado el 2 de julio de 2012 de <http://ec.europa.eu/energy/studies/energy_en.htm>.
} 
aplica el marco legal europeo, incluido el derecho ambiental, a las operaciones de prospección y explotación de gas de esquisto, tomando como referencia a cuatro Estados miembros de la UE (Polonia, Francia, Alemania y Suecia). En claro contraste con el primer informe del Parlamento Europeo, el estudio de la Comisión concluye que el marco legal aplicable a la explotación de hidrocarburos no convencionales es suficiente y apropiado y que, por lo tanto, no es necesaria una legislación específica de la Unión Europea sobre la materia.

\subsection{Segundo informe del Parlamento Europeo}

La Comisión de Industria, Investigación y Energía del Parlamento Europeo elaboró en marzo de 2012 un "Proyecto de informe sobre aspectos industriales, energéticos y otros del gas y el aceite de esquisto", del que ha sido ponente la parlamentaria griega $\mathrm{N}$. TZAVELA. Se trata de un estudio centrado en los aspectos económicos de las explotaciones de gas no convencional y bastante optimista, por cierto, en relación con "el papel fundamental de la producción mundial de gas de esquisto para garantizar la seguridad y diversidad energéticas a largo plazo, también en Europa" ${ }^{25}$. Aunque es una afirmación muy controvertida y desmentida por estudios fiables ${ }^{26}$, el informe defiende que "el desarrollo del gas de esquisto en la UE ayudará a alcanzar el objetivo de la Unión de reducir las emisiones de gases de efecto invernadero entre un $80 \%$ y un $95 \%$ de aquí a 2050". Coincide con la Comisión en que el gas de esquisto "resultará fundamental para la transformación del sistema energético", limitando "la dependencia de otros combustibles fósiles más contaminantes" ${ }^{\text {27 }}$. Este segundo informe contiene algunas recomendaciones relativas al marco jurídico de los permisos de hidrocarburos y, aunque insta a los Estados miembros a mejorar los procedimientos administrativos, considera que "el marco reglamentario de la UE es adecuado para una exploración temprana" de los recursos no convencionales ${ }^{28}$.

\footnotetext{
${ }^{25}$ PARLAMENTO EUROPEO, "Proyecto de informe sobre aspectos industriales, energéticos y otros del gas y el aceite de esquisto" (2011/2309[INI]), 2012. Recuperado el 2 de julio de 2012 de $<$ www.europarl.europa.eu $>$.

${ }^{26}$ El propio Parlamento Europeo había negado en su primer informe que la producción de gas no convencional en Europa contribuyera a reducir la necesidad de importar gas natural. Vid. PARLAMENTO EUROPEO, "Repercusiones de la extracción de gas..." cit. p. 79.

${ }^{27}$ PARLAMENTO EUROPEO, "Proyecto de informe sobre aspectos industriales..." cit., p. 5.

${ }^{28}$ Ibid., p. 7.
} 


\subsection{Tercer informe del Parlamento Europeo}

Por último, el Parlamento presentó en abril de 2012 un "Proyecto de informe sobre las repercusiones medioambientales de la extracción de gas y petróleo de esquisto", elaborado por el eurodiputado polaco B. SONIK y aprobado por mayoría en septiembre de 2012 en el seno de la Comisión de Medio Ambiente, Salud Pública y Seguridad Alimentaria $^{29}$. El documento ha sido recibido con duras críticas por las asociaciones ecologistas europeas, que consideran que promueve la expansión del gas de esquisto en Europa e ignora los riesgos y los impactos negativos del fracking, a la par que defiende los intereses de la industria ${ }^{30}$. Quizás haya tenido algo que ver el hecho de que el ponente sea de origen polaco, un país entusiasta de las nuevas fuentes de energía no convencionales. Este tercer informe del Parlamento se limita a ofrecer consideraciones generales sobre la explotación de hidrocarburos no convencionales, minimizando sus riesgos ambientales y ensalzando la importancia del gas no convencional como fuente de abastecimiento para Europa. Afirma, en concreto, que "ninguna fuente oficial o reconocida de ningún tipo ha demostrado la existencia de relaciones sistemáticas entre la extracción de gas de esquisto y petróleo de esquisto y la salud humana o animal, y que tampoco se ha mostrado en ningún caso que la fractura hidráulica haya causado la contaminación de agua potable"31.

\section{Lagunas del marco normativo europeo}

Ya he avanzado que no existe una normativa especial que regule la explotación de recursos no convencionales mediante fracking en el ámbito de la Unión Europea.

La legislación minera es competencia de los Estados miembros (artículo 194.2 del Tratado de Funcionamiento de la Unión Europea, en adelante, TFUE); aunque existe un

\footnotetext{
${ }^{29}$ PARLAMENTO EUROPEO, "Proyecto de informe sobre las repercusiones medioambientales de la extracción de gas y petróleo de esquisto" (2011/2308[INI]), de 11 de abril de 2012. Recuperado el 2 de julio de 2012 de <www.europarl.europa.eu>.

${ }^{30}$ Una coalición de organizaciones no gubernamentales en los ámbitos del medio ambiente y la salud, integrada, entre otras, por Greenpeace y Ecologistas en Acción, ha aprobado la "Declaración sobre el petróleo y el gas de esquisto, el metano procedente de yacimientos de carbón y la fractura hidráulica", que critica la falta de transparencia y participación ciudadana en las decisiones relativas a la explotación de los hidrocarburos de esquisto, y exhorta a los Estados europeos a suspender todas las actividades en curso, derogar los permisos y prohibir todos los proyectos nuevos de prospección y explotación.

${ }^{31}$ PARLAMENTO EUROPEO, "Proyecto de informe sobre las repercusiones medioambientales..." cit., p. 10 .
} 
reducido marco común de la UE aplicable a las actividades extractivas ${ }^{32}$, ni tiene en cuenta las peculiaridades de la fractura hidráulica, ni refleja, en muchos casos, las necesidades actuales del sector minero ${ }^{33}$. El marco normativo comunitario para la explotación de recursos no convencionales está integrado por las directivas y los reglamentos sobre medio ambiente y protección de la salud. En ámbitos tales como la protección del agua, la evaluación de impacto ambiental, las emisiones contaminantes, la evaluación estratégica, la responsabilidad ambiental, la conservación de los hábitats naturales y de la fauna y flora silvestres, los residuos, el ruido, la seguridad en el trabajo y los accidentes producidos por sustancias peligrosas, el primer informe del Parlamento Europeo identifica al menos 40 actos legislativos comunitarios que serían aplicables a la extracción de recursos no convencionales ${ }^{34}$.

Con todo, que exista un número elevado de normas comunitarias aplicables a la minería no significa que el marco normativo vigente se adapte a las necesidades de la industria extractiva ni, en particular, a la explotación de los hidrocarburos no convencionales, que plantean nuevos retos a los que la legislación europea no ofrece adecuada respuesta. Los informes de las instituciones de la UE ponen de relieve ciertas lagunas de la normativa ambiental cuando se aplican a la explotación no convencional de recursos. ${ }^{\text {Por ejemplo, }}$ la Directiva 2011/92/UE (texto codificado) limita la evaluación de impacto ambiental a los pozos que extraigan más de $500.000 \mathrm{~m}^{3}$ de gas natural por día (ANEXO I, punto 14). Pero como los yacimientos no convencionales, debido a las dificultades de la técnica de extracción, no alcanzan este límite diario, quedan fuera de la evaluación de impacto ambiental (EIA). El primer informe del Parlamento Europeo cree que deberían reconsiderarse estos umbrales para incluir la fractura hidráulica, puesto que la explotación no convencional requiere la instalación de un gran número de pozos que, pese a su baja tasa de extracción, tienen graves repercusiones sobre el paisaje, el consumo de agua y los recursos naturales. Asimismo, el informe sugiere revisar el ámbito de aplicación de la Directiva Marco del Agua (Directiva 2000/60/CE) y prestar

\footnotetext{
${ }^{32}$ Me refiero a la Directiva sobre residuos mineros (DUE 2006/21/CE, de 15 de marzo) y a la Directiva de Hidrocarburos (DUE 1994/22/CE, de 30 de mayo), además de otras disposiciones relativas a la seguridad y salud de los trabajadores de las minas. Existe también una propuesta de Reglamento sobre la seguridad de las actividades de prospección, exploración y producción de petróleo y de gas mar adentro (COM(2011) 688 final, de 27 octubre 2011).

${ }^{33}$ Véase PARLAMENTO EUROPEO, “Repercusiones de la extracción de gas...” cit., p. 49.

${ }^{34}$ Ibid. p. 51.
} 
especial atención a las actividades de fractura y sus posibles consecuencias para las aguas de superficie ${ }^{35}$.

Se propone también valorar la prohibición de usar productos tóxicos en los líquidos de inyección $\mathrm{o}$, al menos, dar a conocer las sustancias químicas que se utilizan en el proceso, restringiendo y controlando el número de productos químicos permitidos ${ }^{36}$. En este sentido, aconseja recopilar y analizar estadísticas sobre accidentes vinculados a la fractura hidráulica, encomendando esta tarea a una autoridad independiente ${ }^{37}$. La nueva Directiva comunitaria sobre accidentes graves (Directiva 2012/18/UE) excluye de su ámbito de aplicación — igual que la Directiva Seveso II, ahora derogada - a la mayor parte de actividades mineras y de explotación de hidrocarburos y gas natural (art. 2.2 letras e), f), g) y h), así que habría sido conveniente revisar su aplicación a la vista de los riesgos potenciales derivados de la fractura hidráulica.

La constatación de estas lagunas conduce a plantear si es conveniente o no elaborar una normativa comunitaria sobre la fractura hidráulica. Los informes elaborados recientemente por las instituciones comunitarias proponen soluciones divergentes al respecto. El primer informe del Parlamento Europeo se muestra favorable a que la UE tome la iniciativa en esta tarea, concluyendo que "debido al complejo carácter de las posibles repercusiones y riesgos para el medio ambiente y la salud humana de la fractura hidráulica, habría que examinar la posibilidad de adoptar una nueva Directiva a nivel europeo para regular exhaustivamente todas las cuestiones relacionadas con este ámbito" $"$.

Personalmente, opino que no es necesario que la UE disponga de una normativa sectorial sobre la fractura hidráulica. Si la disyuntiva es adaptación (de la normativa minera y ambiental) frente a reconstrucción (nueva normativa sectorial), me inclino por la simple adaptación. Dicho esto, considero que sí resulta inaplazable seguir profundizando en el conocimiento de las técnicas, en la situación de los yacimientos no convencionales y en la evaluación de sus riesgos (conocidos, potenciales o hipotéticos), promoviendo estudios rigurosos que permitan adaptar, en su caso, la normativa

\footnotetext{
${ }^{35} I b i ́ d$., p. 61.

${ }^{36}$ Ibíd., p. 62.

${ }^{37}$ Ibíd., p. 83.

${ }^{38}$ Ibíd., p. 83.
} 
ambiental aplicable a las explotaciones que utilizan fractura hidráulica. Y creo también que los Estados miembros deberían paralizar, de acuerdo con el principio de precaución, los permisos de investigación que utilicen técnicas de estimulación por fractura, como han hecho Francia y Bulgaria.

En especial, habría que hacer un esfuerzo por homogeneizar los términos jurídicos a nivel comunitario. Si bien la expresión recurso "no convencional" tiene un significado relativamente homogéneo en el ámbito extrajurídico (basado, como he dicho, en la técnica de extracción mediante estimulación de la roca madre y fractura hidráulica), ninguna normativa europea define este término a efectos jurídicos. La distinción entre recursos convencionales y no convencionales carece de relevancia jurídica, ya que no existen requisitos diferenciados para ambas categorías ni títulos mineros diferentes en función de la técnica de extracción, convencional o no. Todo ello dificulta la identificación de las operaciones mineras que implican el uso de la fractura hidráulica, como veremos a continuación en los casos concretos de Francia o de España.

\section{LA PROHIBICIÓN LEGAL DE LA FRACTURA HIDRÁULICA EN FRANCIA}

Francia es el primer país europeo que ha prohibido por ley la extracción de hidrocarburos mediante fractura hidráulica ${ }^{39}$. El presidente francés, F. Hollande, anunciaba durante la apertura de una conferencia sobre el medio ambiente celebrada en París el 14 de septiembre de 2012, que "no hay nadie que pueda afirmar que la explotación de gas y petróleo de pizarra por fractura hidráulica, única técnica conocida hasta el momento para su extracción, está exenta de riesgos para la salud y el medio ambiente ${ }^{, 40}$. Probablemente el interés suscitado en el país vecino tenga que ver con el hecho de que, junto con Polonia y Estonia ${ }^{41}$, es uno de los Estados con mayores reservas

\footnotetext{
${ }^{39}$ Siguiendo la estela de Francia, Bulgaria ha prohibido también la extracción no convencional mediante fractura hidráulica. En enero de 2012 el Parlamento búlgaro adoptó esta decisión ante los riesgos ambientales del fracking (nota de prensa de la agencia Reuters, en <www.reuters.com>).

${ }^{40}$ El diario Le Monde, en su edición de 17 de septiembre de 2011 (<www.lemonde.fr>), califica estas declaraciones como "el compromiso verde" del presidente francés.

${ }^{41}$ Según el PARLAMENTO EUROPEO, "Proyecto de informe sobre aspectos industriales..." cit., p. 4 y la AGENCIA INTERNACIONAL DE LA ENERGÍA, “Golden Rules...” cit., p. 120, Estonia y Polonia son los países europeos con mayores reservas de hidrocarburos no convencionales y donde se localizan la mitad de las perforaciones exploratorias que se hacen en Europa. En Polonia, al contrario que en Francia, el Gobierno impulsa activamente la extracción de yacimientos no convencionales como una solución a la
} 
de gas no convencional de Europa. Tampoco debemos olvidar que la preocupación por la dependencia energética en Francia es menor que en otros países de Europa debido a la relevancia de la energía nuclear (el 75\% del consumo energético en Francia procede de las centrales nucleares, siendo el segundo productor mundial de este tipo de energía). La sensibilidad ambiental que ha llevado al legislador francés a prohibir la técnica del fracking para los hidrocarburos no convencionales se diluye y desaparece cuando nos situamos en el ámbito de la energía nuclear.

\section{Alcance y justificación de la prohibición legal}

La Ley 2011-835, de 13 de julio de 2011, publicada en el Diario Oficial de 14 de julio de 2011 (corrección de errores en el Diario Oficial de 11 agosto) y tramitada por el procedimiento de urgencia, es el fruto consensuado de cinco proposiciones de ley presentadas ante la Asamblea Nacional y el Senado entre los meses de marzo y abril de 2011. Se trata de una ley muy breve de tan solo cuatro artículos. Su artículo 1 prohíbe en todo el territorio francés la exploración y explotación de minas de hidrocarburos líquidos o gaseosos mediante la técnica de fractura hidráulica. El informe elaborado por los promotores de la Ley ante la Asamblea Nacional subraya que la prohibición afecta a la técnica empleada (la fractura hidráulica) y no al tipo de recurso extraído ${ }^{42}$. Pero, si bien es cierto que la fractura hidráulica se emplea también para mejorar la productividad de los pozos llamados convencionales, su prohibición hace imposible en Francia la exploración y explotación de los yacimientos no convencionales a partir del momento de entrada en vigor de la Ley.

La prohibición absoluta se justifica formalmente en la "aplicación de la Carta del Medio Ambiente de 2004 y del principio de acción preventiva y de corrección previsto en el

\footnotetext{
dependencia energética de Rusia, de la que actualmente importa alrededor del $70 \%$ del gas y más del $80 \%$ del petróleo. Sin embargo, las expectativas iniciales parecen haberse desinflado, ya que el Instituto Geológico Polaco ha revelado que el yacimiento de gas de esquisto que alberga el subsuelo del país es diez veces menor de lo que señalaban las primeras estimaciones (noticia publicada en el diario POLSKA VIVA el 21 de marzo 2012, disponible en <http://polskaviva.com>).

${ }^{42}$ Para descubrir el iter parlamentario y la voluntad del legislador francés, resulta sumamente útil la lectura del "Rapport $n^{\circ} 3392$ sur la Proposition de Loi [...]", de 4 de mayo de 2011, elaborado por M. HAVARD y J.P. CHANTEGUET, de la Comisión de Desarrollo Sostenible y Ordenación del Territorio de la Asamblea Nacional, especialmente las páginas 23 a 36 (disponible en <www.assembleenationale.fr/13/rapports/r3392.asp $>$ ). El esquema completo de los trabajos parlamentarios en $<$ www.assembleenationale.fr/13/dossiers/interdiction_exploration_exploitation_hydrocarbures_non_conventionnels.asp $>$.
} 
art. L.110-1 del Código del Medio Ambiente". Aunque la Ley 2011-835 no hace una alusión directa al principio de precaución del artículo 5 de la Carta constitucional del Medio Ambiente, ya que dicha mención expresa se retiró en su tramitación parlamentaria, parece ser el verdadero fundamento de las medidas adoptadas. En virtud del principio de precaución, que no requiere ningún desarrollo legislativo para hacerlo efectivo, "cuando un daño incierto, según el estado de los conocimientos científicos, pueda afectar de manera grave e irreversible al medio ambiente, las autoridades públicas, en el ámbito de sus competencias, velarán por la puesta en marcha de procedimientos de evaluación de riesgos y la adopción de medidas provisionales y proporcionadas para evitar el daño". La jurisprudencia comunitaria coincide en afirmar que ante un riesgo incierto resulta ineludible realizar una correcta evaluación de este, quedando su gestión sometida a la discrecionalidad de la autoridad pública competente ${ }^{43}$.

Pero ¿cómo se ha realizado la evaluación de los riesgos (inciertos o conocidos) de la fractura hidráulica en Francia? El legislador tomó la iniciativa en esta tarea evaluadora encomendando a una "misión informativa" de la Comisión de Economía, Desarrollo Sostenible y Ordenación del Territorio de la Asamblea Nacional la elaboración de un estudio informativo sobre los hidrocarburos de esquisto, que se presentó el 8 de junio de 2011, cuando ya la Ley estaba a punto de terminar su tramitación parlamentaria ${ }^{44}$. Paralelamente, en febrero de 2011 el Gobierno francés encargaba a representantes del Consejo General de Economía, Industria, Energía y Tecnologías (CGIET) y del Consejo General de Medio Ambiente y Desarrollo Sostenible (CGEDD) la elaboración de otro informe, que fue presentado en febrero de 2012 $2^{45}$. También el Ministerio de Medio Ambiente y Desarrollo Sostenible encomendó a un conjunto de expertos del Bureau de Recherches Géologiques et Minières (BRGM) y otros organismos públicos de referencia en el ámbito de las ciencias de la tierra y el medio ambiente la elaboración de

\footnotetext{
${ }^{43}$ Al respecto, EMBID TELLO, Precaución y Derecho. El caso de los campos electromagnéticos, Iustel, Madrid, 2010, p. 561.

${ }^{44}$ Rapport d'Information, núm. 3517, de la Asamblea Nacional, elaborado por F-M. GONNOT y P. MARTIN, 2011. Recuperado el 3 de julio de 2012 de <www.assemblee-nationale.fr/13/rapinfo/i3517.asp>.

45 "Les hydrocarbures de roche-mère en France. Rapport initial et rapport complementarie", elaborado por J.P. LETEURTROIS, D. PILlET, J.L. DURVILlE, J.C. GAZEAU, G. BELLEC, S. CATOIRE, 2012. Recuperado el 3 de julio de 2012 de <www.ladocumentationfrancaise.fr/rapportspublics/124000163/index.shtml>.
} 
un rapport sobre los riesgos de la explotación de hidrocarburos no convencionales ${ }^{46}$. Los sucesivos informes elaborados a iniciativa del legislador o del Gobierno francés ofrecen datos relativos a las reservas de yacimientos no convencionales, al impacto económico y ambiental de su explotación y al marco legal aplicable, con referencias cruzadas entre ellos y también con alusiones a otros estudios elaborados por organismos de EE. UU., país pionero en el empleo de la fractura hidráulica. El problema radica en que todos ellos se han presentado en un momento posterior a la promulgación de la Ley 2011-835, o sin haber terminado los trabajos parlamentarios. Por eso, se ha criticado que la urgencia en la tramitación de la ley ha hecho difícil, cuando no imposible, incorporar las recomendaciones de dichos informes ${ }^{47}$.

En cualquier caso, con la promulgación de la Ley 2011-835 el legislador francés ha optado por una prohibición total de la fractura hidráulica, valorando que las incertidumbres relativas a los riesgos del fracking y las deficiencias de su marco legal hacen que aquella sea la "mejor solución" según el principio de precaución ${ }^{48}$. Los debates parlamentarios ilustran que las medidas legales se justificarían por su carácter provisional y de urgencia.

No ha sido una decisión pacífica ni bien recibida por una parte de la comunidad científica. Ya a lo largo de la tramitación parlamentaria de la Ley se oyeron voces contrarias a su prohibición con el argumento de que no existen evidencias científicas claras sobre los riesgos ambientales y sanitarios de la fractura hidráulica. Los ponentes que han intervenido en los trabajos legislativos insisten en la necesidad de profundizar en estudios que ayuden a comprender mejor dichos riesgos ${ }^{49}$. Especialmente crítico con la forma en que se ha aplicado el principio de precaución en el ámbito de la fractura hidráulica se muestra el estudio informativo realizado por la Comisión parlamentaria de Evaluación y Control de las Políticas Públicas de la Asamblea Nacional, que considera que "se ha legislado con precipitación, bajo el impulso de la emoción y con

\footnotetext{
46 "Maitrise des impacts et des risques liés à l'exploitation des hydrocarbures de roche-mère: enjeux, verrous et pistes de recherche. Rapport final" (BRGM/RP-60312-FR), elaborado por L. DE LARY, H. FABRIOL, I. MORETTI, F. KALAYDJIAN, C. DIDIER, 2011. Recuperado el 3 de julio de 2012 de <www.brgm.fr/publication/pubDetailRapportSP.jsp?id=RSP-BRGM/RP-60312-FR>.

47 "Rapport $n^{\circ}$ 556, fait au nom de la commission de l'économie, du développement durable et de l'aménagement du territoire", elaborado por el senador M. HOUEL, de 25 de mayo de 2011, p. 15. Recuperado el 3 de julio de 2012 de <www.senat.fr/rap/110-556/110-556.html >.

48 "Rapport no $3392 . . . "$ cit., p. 31.

${ }^{49}$ Ibid., p. 13.
} 
fundamentos de dudosa racionalidad" 50 . Porque una cosa son los "riesgos inciertos" que legitiman la aplicación del principio de precaución y otra los "riesgos probados" que conducen a aplicar medidas preventivas. El informe critica especialmente que la Ley se haya aprobado sin tener en cuenta las conclusiones de la "misión informativa" nombrada al efecto. La precipitación mostrada por el legislador ofrece una imagen distorsionada del principio de precaución, que no es un principio de urgencia. Por otro lado, la doble justificación de la prohibición del fracking en el principio de precaución y en el de prevención (art. 1 de la Ley 2011-385) resulta confusa desde un punto de vista jurídico, pues ambos principios, si bien recogidos en el mismo precepto del Código del Medio Ambiente (art. L.110-1), no obedecen a los mismos presupuestos ni permiten adoptar las mismas medidas ante riesgos emergentes ${ }^{51}$.

Volviendo al análisis de la Ley 2011-835, hay que decir que la prohibición no tiene efecto inmediato, pues el artículo 3 prevé un plazo de dos meses desde su promulgación (que expiró el 13 de septiembre 2011) para que los titulares de permisos exclusivos de investigación de hidrocarburos remitan a la autoridad competente un informe donde se detallen "las técnicas empleadas o proyectadas en el ámbito de sus actividades de investigación". No deja de resultar curioso, siguiendo a GOSSEMENT, que la prohibición legal vaya seguida de un acto administrativo de revocación diferido en dos meses y condicionado a la intervención del propio titular del permiso, como si la revocación de los permisos dependiera de la decisión de sus titulares ${ }^{52}$. La Administración competente en materia energética recibió 64 informes, correspondientes a otros tantos permisos vigentes, y mediante ârreté de 12 de octubre de 2011 se revocaron tres de ellos, los relativos a explotaciones de gas de esquisto que utilizaban la técnica de la fractura hidráulica. Los titulares de los otros 61 permisos de hidrocarburos que siguen vigentes, por su parte, se han comprometido formalmente a no utilizar la fractura hidráulica y limitarse a los yacimientos convencionales.

\footnotetext{
50 “Rapport d'Information no 3970 sur l'évaluation de la mise en oeuvre de l'article 5 de la Charte de l'environnement relatif à l'application du principe de précaution", 2011, realizado por los diputados GEST y TOURTELIER, especialmente pp. 11 a 21, 64 y 69. Recuperado el 2 de julio de 2012 de $<$ www.assemblee-nationale.fr/13/rap-info/i3970.asp $>$.

${ }^{51}$ Sobre esta distinción, por todos, EMBID TELLO, Precaución ... cit., p. 179.

${ }^{52}$ GOSSEMENT, "Droit minier et droit de l'environnement. Eléments de réflexion pour une réforme relative à l'évaluation environnementale, à l'information et à la participation du public. Rapport remis à Madame Nathalie Kosciusko-Morizet, Ministre de l'Ecologie, du Développement durable, des Transports et du Logement", París, 2011, p. 182. Recuperado el 4 de julio de 2012 de <www.developpementdurable.gouv.fr/>.
} 
A lo largo de los trabajos parlamentarios se debatió la posibilidad de que los titulares de permisos revocados pudieran solicitar una indemnización por daños en aplicación del régimen de responsabilidad patrimonial derivada de actos legislativos. Si bien los parlamentarios consideraron que la cuantificación del daño no era sencilla, pues los titulares de un permiso de investigación no tienen derecho a explotar el yacimiento, sí resulta efectivo el perjuicio derivado por la pérdida de la inversión realizada $y$, sobre todo, el daño causado a los titulares de concesiones de hidrocarburos convencionales que no podrán utilizar la fractura hidráulica para mejorar la productividad de sus explotaciones $^{53}$. También la doctrina considera problemática, desde un punto de vista jurídico, la revocación de los títulos ya concedidos ${ }^{54}$.

La Ley 2011-835 crea la Comisión Nacional de Orientación, Seguimiento y Evaluación de las Técnicas de Exploración y Explotación de Hidrocarburos, a la que se atribuye la función de "evaluar los riesgos ambientales asociados a las técnicas de fractura hidráulica o técnicas alternativas" (art. 2). Una nueva comisión que, a juicio de GOSSEMENT, no contribuye a la mejora del marco jurídico, sino solo a la multiplicación de órganos administrativos ${ }^{55}$. Además, sus competencias no son exclusivamente consultivas, ya que la Ley 2011-835 prevé la intervención de la Comisión Nacional para autorizar aquellas operaciones de fractura hidráulica realizadas con fines científicos bajo control público, previstas en el artículo 4. La composición y el funcionamiento interno de dicha Comisión se regulan por el Decreto 2012-385, de 21 de marzo.

Como digo, la prohibición legal tiene una importante excepción: la posibilidad de que, bajo las condiciones que fije el Gobierno, se pongan en marcha proyectos de exploración o explotación de yacimientos no convencionales "a los solos efectos de investigación científica y bajo control público". Ya el informe de la comisión de expertos que se presentó en febrero de 2012 por encargo del Gobierno francés recomendaba a los poderes públicos la puesta en marcha de un "programa de investigación científica", nacional o europeo, sobre la técnica de la fractura hidráulica y su impacto ambiental, con el objetivo de ampliar el conocimiento geológico e

\footnotetext{
53 “Rapport n' 556...” cit., pp. 17-18.

${ }^{54}$ Por todos, BILLET, "Le nouveau Code Minier et l'exploitation du gaz de schiste", La Semaine Juridique-Administration et Collectivités Territoriales, núm. 17, 2011, p. 34.

${ }^{55}$ GOSSEMENT, “Droit minier et droit de l'environnement...” cit., p. 182.
} 
hidrogeológico de los yacimientos no convencionales, profundizar en las mejores técnicas disponibles, mejorar su marco jurídico y extremar los controles de la policía de minas $^{56}$. Pues bien, el artículo 4 de la Ley 2011-835 dispone que "el Gobierno remitirá anualmente al Parlamento un informe sobre la evolución de las técnicas de exploración y explotación y el conocimiento del subsuelo francés, europeo e internacional en materia de hidrocarburos líquidos o gaseosos, sobre las condiciones para la puesta en marcha de experimentaciones realizadas a los solos efectos de investigación científica bajo control público, sobre los trabajos de la Comisión Nacional creada en el artículo 2, sobre la adecuación del ordenamiento jurídico minero a la Carta del Medio Ambiente y sobre las adaptaciones legislativas o reglamentarias realizadas". Además de la obligación de elaborar este informe anual, el precepto destaca por abrir la puerta a operaciones de exploración o investigación de hidrocarburos "realizadas a los solos efectos de investigación científica", que se someten al control de la Comisión Nacional. Para GOSSEMENT, esta confusa derogación de la prohibición inicial de la Ley plantea numerosas dudas, como la definición misma de "experimentación científica" que permitiría desarrollar en Francia la técnica de la fractura hidráulica ${ }^{57}$.

\section{Insuficiencias del nuevo Code Minier francés}

La investigación y explotación de los hidrocarburos se regula en la parte legislativa del nuevo Code Minier francés (art. L-111.1.1º), que parte de una distinción entre dos clases de títulos mineros ${ }^{58}$ :

a) Los permisos exclusivos de investigación (permis exclusifs de recherches) se otorgan por acuerdo ministerial y por un período máximo de cinco años, renovable (arts. L-

\footnotetext{
56 “Les hydrocarbures de roche-mère en France..." cit., pp. 73 y 74. El informe aconsejaba crear un "comité científico nacional" integrado por técnicos de las instituciones públicas de referencia en el ámbito de la energía y las ciencias de la tierra (Bureau de Recherches Géologiques et Minières, BRGM; IFP Energies nouvelles; e Institut National de l'Environnement Industriel et des Risques, INERIS), junto con expertos universitarios, encargado de velar por la calidad y la transparencia de las investigaciones relacionadas con los hidrocarburos no convencionales.

${ }^{57}$ GOSSEMENT, “Droit minier et droit de l'environnement...” cit., p. 180.

${ }^{58} \mathrm{He}$ consultado la versión consolidada del nuevo Código Minero (recuperado el 7 de septiembre de 2012 de $<$ http://www.legifrance.gouv.fr $>$ ). La primera versión del Code Minier fue aprobada por Decreto 56838, de 16 de agosto de 1956, y desde entonces ha sufrido numerosas modificaciones. La última codificación de la parte legislativa del Code Minier fue aprobada mediante Ordenanza 2011-91, de 20 de enero de 2011, poco antes de la prohibición legal de la fractura hidráulica (Diario Oficial de 25 enero 2011).
} 
122.1 a L-122.3). El procedimiento administrativo no contempla el trámite de información pública, hecho que constituye uno de los puntos negros de la crítica doctrinal.

b) La concesión confiere a sus titulares el derecho de extraer y explotar el recurso situado en el subsuelo. Se otorga mediante Decreto del Gobierno, previo informe del Consejo de Estado, por un plazo máximo de 50 años (arts. L-131-1 a L-132-7). El procedimiento concesional sí contempla un período de información pública, que en el caso de los hidrocarburos se hace mediante la simple publicación de un aviso en el Diario Oficial de la República Francesa y en el de la Unión Europea, salvo que sus titulares lo sean ya de un permiso exclusivo de investigación (art. L. 132-6). El estudio informativo elaborado por los diputados Gonnot y Martin por encargo de la Asamblea Nacional critica el otorgamiento casi automático de la concesión minera al titular del permiso de investigación y propone una reforma del código minero que permita a las autoridades competentes rechazar los títulos mineros por razones de oportunidad ${ }^{59}$.

En derecho francés el otorgamiento de un título minero tiene, digamos, simples efectos "patrimoniales": la privación al propietario del suelo de sus derechos sobre los recursos del subsuelo, pero no autoriza a sus titulares a iniciar los trabajos mineros. Los trabajos de investigación y/o de explotación quedan subordinados a un régimen de autorización o a una simple declaración administrativa en el marco de la denominada "policía de minas" (arts. L-171-1 y -2). Mientras que el procedimiento de autorización exige estudios de impacto, información pública y consultas a las distintas administraciones implicadas (comunas, departamentos y Administración hidráulica), la declaración sigue un procedimiento simplificado sin apenas requisitos de participación y publicidad. Pues bien, el inicio de trabajos de investigación de hidrocarburos, convencionales o no, queda sujeto a simple declaración, escapando así a la información pública.

Tras la promulgación de la nueva Ley 2011-835 relativa a la prohibición del fracking, la doctrina francesa considera inaplazable una nueva reforma del Código Minero francés, que habría quedado obsoleto y desfasado ${ }^{60}$. Las críticas se centran, sobre todo, en que el Code Minier no permite la participación pública en la toma de decisiones relativas a los

\footnotetext{
59 “Rapport d'Information n $3517 \ldots$... cit., p. 84.

${ }^{60}$ GOSSEMENT, “Droit minier et droit de l'environnement...” cit., p. 359, y BILLET, "Le nouveau Code Minier..." cit., p. 32.
} 
permisos de hidrocarburos, en la poca transparencia del procedimiento administrativo y en la falta de adaptación a los requerimientos ambientales. Los ponentes del informe encargado por el Gobierno critican que el Code Minier no haya incorporado la evolución fundamental de la organización territorial francesa después de treinta años de descentralización, que ha confiado a las colectividades territoriales importantes competencias sobre el medio ambiente. Por eso, no tiene sentido que estas colectividades territoriales no puedan participar en el procedimiento para la puesta en marcha de los trabajos de exploración de hidrocarburos, especialmente cuando se emplea la técnica de la fractura hidráulica, ahora prohibida por Ley 2011-835 ${ }^{61}$. A pesar de la última reforma de 2011, los rapports informativos elaborados por la Asamblea Nacional y por el Gobierno francés consideran que hay que avanzar más, que es necesario mejorar la transparencia de los procedimientos relativos a los permisos y los trabajos mineros e incorporar las exigencias ambientales, que actualmente no solo incumplen la Directiva 2003/4/CE, sobre información ambiental, sino también la Convención de Aarhus, ratificada por la UE, y, por supuesto, la propia Carta constitucional del Medio Ambiente (art. 7) ${ }^{62}$.

Los permisos de investigación se otorgan sin ofrecer información apropiada sobre las técnicas empleadas y las consecuencias potenciales sobre el medio ambiente y el paisaje. Los ciudadanos y las colectividades afectados tienen la sensación de haber quedado al margen de los impactos reales de la exploración de gas y petróleo de esquisto. El problema es que el Code Minier francés no contempla la información pública para el otorgamiento de permisos de exploración, ni siquiera para iniciar los trabajos mineros de perforación. Durante la tramitación parlamentaria de la Ley 2011835 se puso de manifiesto que el carácter inédito de la técnica de la fractura hidráulica en territorio francés habría justificado ir más allá de procedimientos rígidos concebidos en una época en la que las técnicas convencionales de extracción eran las únicas que se desarrollaban.

\footnotetext{
61 "Les hydrocarbures de roche-mère en France..." cit., p. 62.

${ }^{62}$ Durante la legislatura anterior el Gobierno presentó ante la Asamblea Nacional el proyecto de Ley núm. 3338, de 13 de abril de 2011, para mejorar la participación pública en los procedimientos mineros, pero fue retirado en mayo de 2012 (<www.assembleenationale.fr/13/dossiers/ratification_ordonnance_201191.asp $>$ ). Así que las insuficiencias denunciadas del Code Minier, relativas a su falta de transparencia y participación, siguen plenamente vigentes.
} 
En este sentido, el extenso informe de GOSSEMENT realizado por encargo del Ministerio de Medio Ambiente francés, con cuarenta propuestas concretas de reforma del derecho minero, defiende que sería conveniente integrar completamente el derecho minero en el derecho ambiental; ello comporta no solo negar la autonomía del derecho minero, sino también transferir las competencias mineras que hasta ahora tienen las autoridades en materia energética a las administraciones ambientales ${ }^{63}$. Este autor, por cierto, propone calificar todos los recursos mineros como "patrimonio común", en el sentido que recoge la Carta constitucional del Medio Ambiente, nuevo concepto jurídico de vocación transnacional y no limitado por concepciones patrimonialistas ${ }^{64}$. Además, el estudio informativo de GONNOT y MARTIN reclama una mayor precisión técnica a la hora de conceder los permisos relativos a los hidrocarburos que incluya una definición de los hidrocarburos no convencionales a efectos legislativos, pues el Código vigente trata los hidrocarburos como un recurso único, sin consideración de las técnicas empleadas $^{65}$.

\section{LA FRACTURA HIDRÁULICA EN ESPAÑA}

En el derecho español de minas, como ocurre en Francia, no existe un marco jurídico propio para los hidrocarburos no convencionales, cuya explotación se somete al mismo régimen que los convencionales (Ley 34/1998, de 7 de octubre, del Sector de Hidrocarburos, LSHi; RD 2362/1976, de 30 de julio, por el que se aprueba el Reglamento de la Ley sobre Investigación y Explotación de Hidrocarburos, RHi; y demás normativa de desarrollo). En este epígrafe analizaré los presupuestos del debate jurídico sobre la fractura hidráulica en España, centrándome en los permisos solicitados y concedidos en territorio nacional que afectan a los yacimientos no convencionales, para plantear si en nuestro país sería jurídicamente admisible una moratoria o prohibición como en otros Estados miembros de la UE.

Lo cierto es que las reservas españolas de yacimientos de hidrocarburos no convencionales son irrisorias en comparación con Polonia, Francia, Estonia o Alemania, aunque no existen estudios fiables que permitan un conocimiento exacto de tales

\footnotetext{
${ }^{63}$ GOSSEMENT, "Droit minier et droit de l'environnement..." cit., p. 217.

${ }^{64}$ Ibid. p. 234.

65 "Rapport d'Information no $3517 . .$. " cit., p. 91.
} 
recursos. Aunque el "panorama minero" del IGME menciona indirectamente el gas no convencional, el Sistema de Información de Hidrocarburos (SIH), la Base de Recursos Minerales del IGME o el Archivo Técnico de Hidrocarburos, dependiente del Ministerio de Industria, no permiten identificar las reservas de hidrocarburos no convencionales presentes en el territorio nacional ni los títulos mineros que tienen por objeto dichos recursos o emplean la técnica de la fractura hidráulica. Esta falta de datos estadísticos y estudios fiables condiciona cualquier aproximación jurídica a los recursos no convencionales.

\section{Los proyectos en marcha}

En este epígrafe me centraré en los proyectos de investigación y/o explotación de yacimientos de hidrocarburos desarrollados en España en los que hay evidencias de utilización de la técnica del fracking. Y digo bien: se trata, salvo excepciones, de simples evidencias o hipótesis deducibles de indicios o datos secundarios. No es fácil identificar las operaciones que emplean fractura hidráulica porque, con la LSHi y el RHi en la mano, la distinción entre yacimientos convencionales y no convencionales carece de relevancia jurídica. Ni todos los permisos de investigación de hidrocarburos son para recursos no convencionales, ni en los títulos se suele especificar el uso de técnicas de estimulación mediante fractura hidráulica.

Para facilitar este recorrido por los permisos de investigación de hidrocarburos en el mapa español, partiré de la distinción entre aquellos que afectan al territorio de varias comunidades autónomas, cuyo otorgamiento corresponde al Consejo de Ministros mediante Real Decreto (art. 18.2 LSHi); los que afectan al subsuelo marino, que también son competencia del Gobierno mediante Real Decreto; y aquellos otros que se limitan al territorio de una sola comunidad autónoma, en cuyo caso la decisión corresponde al Gobierno autonómico (arts. 3.3 c) y 18.2 LSHi). Las comunidades autónomas con mayor territorio afectado por permisos de investigación de hidrocarburos supuestamente no convencionales son País Vasco, Castilla y León (en especial, la provincia de Burgos), Cantabria, Andalucía, Comunidad Valenciana, La Rioja y Navarra. Aquí voy a analizar algunos de los permisos ya concedidos, advirtiendo que el último mapa del Ministerio de Industria correspondiente a 2012 
anuncia una auténtica avalancha de solicitudes de permisos de investigación de hidrocarburos pendientes de tramitación ${ }^{66}$.

\subsection{Permisos que afectan a varias comunidades autónomas}

Por su enorme impacto mediático, comenzaré por el proyecto denominado Gran Enara, que se extiende sobre una superficie de prospección de 1.400 kilómetros cuadrados en los territorios del País Vasco, Castilla y León, Cantabria y Navarra, aunque ha sido el Gobierno Vasco su principal valedor y cabeza visible.

"Una bolsa de gas hallada en Álava podría abastecer a Euskadi durante 60 años", publicaba el Diario Vasco el 15 de octubre de 2011. Según el entonces lehendakari Patxi López, "este proyecto nos va a permitir ser prácticamente autosuficientes energéticamente y puede ser una actividad tractora de nuestra economía, generando trabajo, empleo y riqueza para el resto de empresas del país”. La Consejería de Industria del Gobierno Vasco calcula que "el proyecto de extracción de gas no convencional en Álava generaría 30.000 millones de euros" ${ }^{\text {67 }}$. El proyecto Gran Enara está integrado por cinco permisos de investigación de hidrocarburos (denominados Enara, Angosto-1, Usoa, Mirua y Usapal), cuya titularidad corresponde a la sociedad pública Sociedad de Hidrocarburos de Euskadi, S. A. (SHESA), participada al 100\% por el Ente Vasco de la Energía (EVE), que es un organismo público adscrito al Departamento de Industria de la Comunidad Autónoma del País Vasco.

\begin{tabular}{|c|c|c|c|c|}
\hline $\begin{array}{l}\text { Nombre } \\
\text { del } \\
\text { permiso }\end{array}$ & $\begin{array}{c}\text { Fecha de concesión y } \\
\text { publicación }\end{array}$ & $\begin{array}{l}\text { Comunidades } \\
\text { autónomas afectadas }\end{array}$ & $\begin{array}{c}\text { Plazo } \\
\text { de } \\
\text { vigencia }\end{array}$ & $\begin{array}{l}\text { Extensión } \\
\text { (ha) }\end{array}$ \\
\hline ENARA & $\begin{array}{l}\text { RD 1399/2006, de } 24 \text { de noviembre (BOE núm. } \\
302 \text {, de } 19 \text { diciembre) } \\
\text { Orden ITC/2242/2011, de } 14 \text { de julio, amplía su } \\
\text { vigencia hasta el 19/06/2014 }\end{array}$ & País Vasco y Castilla y León & 6 años & 75.852 \\
\hline
\end{tabular}

66 Los mapas de los años 2004 a 2012 pueden consultarse en $<$ www.minetur.gob.es/energia/petroleo/Exploracion/Mapa/Paginas/mapSondeos.aspx $>$. Según publica el diario La Vanguardia (26/03/2012), “entre el 2009 y el 2012, los permisos de investigación concedidos por la Administración para hallar petróleo y gas se han incrementado un 60\%. En el 2009, había 47 permisos vigentes y al iniciarse este año ya son 76 ".

67 Son datos del portal electrónico de información institucional del Gobierno Vasco, en $<$ www.irekia.euskadi.net/es/news/8686> (recuperado el 11 de julio de 2012). 


\begin{tabular}{|c|c|c|c|c|}
\hline ANGOSTO-1 & $\begin{array}{l}\text { RD 1400/2006, de } 24 \text { noviembre (BOE núm. } \\
\text { 302, de } 19 \text { de diciembre) }\end{array}$ & $\begin{array}{l}\text { País Vasco, Castilla y León y } \\
\text { Cantabria }\end{array}$ & 6 años & 26.119 \\
\hline USOA & $\begin{array}{l}\text { RD } 56 / 2008 \text {, de } 18 \text { de enero (BOE núm. } 42 \text {, de } \\
18 \text { febrero) }\end{array}$ & $\begin{array}{l}\text { País Vasco, Castilla y León y } \\
\text { Navarra }\end{array}$ & 6 años & 72.691 \\
\hline MIRUA & $\begin{array}{l}\text { RD } 57 / 2008 \text {, de } 18 \text { de enero (BOE núm. } 42 \text {, de } \\
18 \text { febrero) }\end{array}$ & País Vasco y Castilla y León & 4 años & 75.240 \\
\hline USAPAL & $\begin{array}{l}\text { RD } 58 / 2008 \text {, de } 18 \text { de enero (BOE num. } 42 \text {, de } \\
18 \text { febrero) }\end{array}$ & $\begin{array}{l}\text { e País Vasco, Castilla y León y } \\
\text { Cantabria }\end{array}$ & 6 años & 74.934 \\
\hline
\end{tabular}

Tabla 1. Permisos de investigación integrados en Gran Enara (elaboración propia)

Los indicios de yacimientos de gas no convencional, fruto de las primeras prospecciones, mejoraron las expectativas iniciales del Gobierno Vasco, que se comprometía a una nueva inversión para realizar sondeos que determinaran con exactitud los puntos de extracción. SHESA suscribió en 2010 un convenio de colaboración con dos empresas norteamericanas del sector gasístico: Petrichor Euskadi Coöperatief UA, Sucursal en España, y Cambria Europe Inc, Sucursal en España, que adquirieron parte de los activos de la sociedad pública. Y así, mediante Orden IET/564/2012, de 27 de febrero (BOE núm. 68, de 20 marzo), se autorizaba la cesión de la titularidad de los cinco permisos de investigación de hidrocarburos, que quedó de la siguiente manera: el $44 \%$ en manos de SHESA, el 36\% de Petrichor Euskadi y el 20\% de Cambria Europe. No obstante, SHESA mantiene su condición de operador de los permisos. Por otro lado, se autorizaba la acumulación de los cinco permisos - Enara, Angosto-1, Usoa, Mirua y Usapal- por la coincidencia de sus titulares, por su situación geográfica, al ser colindantes, y por tener los mismos objetivos de exploración.

Lo cierto es que los programas de investigación de los cinco permisos que integran GRAN ENARA no mencionan claramente que se vayan a utilizar técnicas de fractura hidráulica. Pero en los BOE de concesión de los distintos permisos sí se puede leer que se realizarán trabajos de "perforación de un sondeo de exploración, posiblemente multilateral, con una profundidad no inferior a 2.000 metros". Los permisos Enara, Mirua, Usapal y Usoa aluden incluso al desarrollo de técnicas de “estimulación”. Puesto que el propio Gobierno Vasco ha confirmado la existencia de yacimientos de gas no convencional, se intuye que se emplearán técnicas de fractura hidráulica. De hecho, el Gobierno Vasco, junto con representantes de la Diputación Foral de Álava y del Ayuntamiento de Vitoria, constituyó en enero de 2012 la Comisión Interinstitucional sobre el Gas no Convencional en Álava, con el objetivo de garantizar que los trabajos exploratorios previstos "supongan una mínima afección para el medio natural, así como 
identificar los potenciales riesgos que se derivarían de posibles trabajos de explotación"

Una característica común de los permisos de investigación concedidos es que exigen un esfuerzo hermenéutico para concluir que tienen por objeto recursos no convencionales y que, por ende, emplearán técnicas de fractura hidráulica. Los programas de investigación, como se ha visto, recurren a expresiones vagas ("sondeos exploratorios", "técnicas de estimulación") que parecen querer desviar la atención del objetivo principal, que es la explotación no convencional de hidrocarburos. Solo algunos planes de trabajo contemplan expresamente el uso de "técnicas de estimulación por fractura", como el del permiso Urraca, de titularidad de la empresa Trofagás Hidrocarburos, S. L., en las comunidades del País Vasco y Castilla y León (RD 1299/2011, de 16 de septiembre).

Otro indicio que permite concluir que la investigación recae sobre recursos no convencionales es el análisis de la empresa titular del permiso, a menudo filial de otras empresas (muchas de ellas norteamericanas) que se dedican a explotar yacimientos no convencionales. Es el caso de los permisos Bezana y Bigüenzo, cuya titularidad comparten Petroleum Oil \& Gas España (50\%), Repsol Investigaciones Petrolíferas, S. A. $(40 \%)$ y Pyrenees Energy Spain, S. A. (10\%), en los territorios de Cantabria y Castilla y León (RD 1781/2009, de 13 de noviembre). No sabemos exactamente qué tipo de investigación llevarán a cabo, pero dado que la empresa Petroleum Oil \& Gas es una filial de Gas Natural, es probable que se dedique a investigar yacimientos de gas de esquisto y que, por eso, recurra a técnicas de estimulación. En las comunidades autónomas de La Rioja y Castilla y León se han concedido los permisos Ebro-B, EbroC, Ebro-D y Ebro-E a las sociedades SHESA, Unión Fenosa y Oil \& Gas Skills (RD 1302/2011, de 16 de septiembre), que contemplan la perforación de un pozo exploratorio que supuestamente exigirá técnicas de estimulación ${ }^{69}$.

\footnotetext{
${ }^{68}$ Para contrarrestar una creciente opinión pública contraria al fracking y defender las bondades del proyecto, la Consejería de Industria del País Vasco, en el marco de la recién creada Comisión Interinstitucional, organizó las Jornadas Técnicas sobre Gas no Convencional. Álava en el Contexto Internacional (abril de 2012).

${ }^{69}$ El documento divulgativo titulado "La extracción de gas no convencional y la fractura hidráulica", de noviembre de 2011, que elaboró la Asamblea contra la Fractura Hidráulica (disponible en $<$ www.fracturahidraulicano.info/documentos.html $>$ ), enumera estos y otros permisos de investigación de hidrocarburos que resultan "sospechosos" de utilizar el método de extracción por fractura hidráulica, denunciando "el silencio y secretismo" que rodean a su concesión.
} 
Rastrear las preguntas e interpelaciones que, en ejercicio de su función de control, realizan los grupos parlamentarios y diputados de las Cortes permite obtener más datos indiciarios. La preocupación por el impacto ambiental de la fractura hidráulica ha llevado a que, entre febrero y julio de 2012, se hayan formulado siete preguntas escritas dirigidas al Gobierno relativas a la fractura hidráulica. L. Tudanca Fernández, diputado del Grupo Parlamentario Socialista en el Congreso, se interesaba, en concreto, por las solicitudes de declaración de impacto ambiental "para algún proyecto de extracción de gas no convencional mediante fractura hidráulica" en las provincias de Burgos y Álava. Las dos preguntas se respondieron lacónicamente afirmando que en la actualidad "no existe ninguna concesión de explotación de gas no convencional que es el único título habilitante para la extracción comercial de hidrocarburos". La respuesta se sale por la tangente ya que, si bien es cierto que solo la concesión habilita para la "extracción" de gas no convencional, no lo es menos que los actuales permisos de investigación de hidrocarburos ocultan operaciones de fractura hidráulica que implican riesgos para el medio ambiente y la salud humana ${ }^{70}$.

Por su parte, C. Yuste Cabello, diputado del Grupo Parlamentario Izquierda Plural, solicitaba al Gobierno información "sobre si alguna empresa ha presentado alguna petición en Aragón para el uso de la técnica extractiva de la fractura hidráulica (o técnica del fracking) para poder extraer gas”, siendo la respuesta escrita idéntica a las relativas a Álava y Burgos e igualmente equívoca ${ }^{71}$.

El Grupo Parlamentario Unión, Progreso y Democracia, a instancia de su diputado C. Martínez Gorriarán, preguntaba acerca de las medidas que tiene previsto adoptar el Gobierno "para garantizar la protección medioambiental en las exploraciones de gas no

\footnotetext{
${ }^{70}$ Preguntas 184/001823 y 184/001824, en BOCG-Congreso, núm. 40-D, de 22 de febrero de 2012, y respuestas en BOCG-Congreso, núm. 117-D, de 27 de junio de 2012. El mismo diputado preguntaba también si se había solicitado al Colegio de Geólogos algún informe sobre la fractura hidráulica para extraer gas no convencional (184/001837), siendo la respuesta que "el Ministerio de Industria, Energía y Turismo (MINETUR) no dispone de información alguna para identificar el ofrecimiento concreto y formal del Colegio de Geólogos al que se refiere la pregunta de Su Señoría. Por otra parte el MINETUR tampoco ha solicitado un informe al Colegio de Geólogos sobre la fracturación hidráulica para extraer gas no convencional".

${ }^{71}$ Pregunta 184/003489, en BOCG-Congreso, núm. 69-D, de 4 de abril de 2012, y respuesta en BOCGCongreso, núm. 128-D, de 16 de julio de 2012. El mismo diputado se había interesado por las peticiones de prospección para la obtención de recursos de hidrocarburos registradas en el Ministerio de Industria, y especialmente sobre si "van a variar los criterios para la obtención de esos permisos reduciéndose las exigencias medioambientales" (pregunta 184/001759, BOCG-Congreso, núm. 40-D, de 22 de febrero de 2012). Pero tampoco la escueta respuesta del Gobierno aclaraba nada al respecto (respuesta en BOCGCongreso, núm. 117-D, de 27 de junio de 2012).
} 
convencional ya concedidas o que se concedan en el futuro", recordando que "la exploración y explotación de los recursos no convencionales se encuentra en un limbo legal por inseguridad jurídica”. El Gobierno, en su respuesta, se limitaba a recordar que los proyectos de perforación para la obtención de gas por fractura hidráulica se someten a EIA, y afirmaba que "cada proyecto se evalúa individualmente, teniendo en consideración sus potenciales impactos específicos sobre el medio ambiente, y el Ministerio de Agricultura, Alimentación y Medio Ambiente, en colaboración con organismos públicos de investigación, está realizando una serie de estudios que permitirán la elaboración de criterios comunes de valoración de los impactos de estas tecnologías de extracción y, en su caso, la adopción de unas adecuadas medidas correctoras" 72 . Al estimar que dicha respuesta era insuficiente, el grupo Unión, Progreso y Democracia formulaba una nueva pregunta relativa a las medidas que adoptará el Gobierno para la protección ambiental de las explotaciones de gas no convencional y, especialmente, si tenía previsto "aprobar una moratoria en la extracción de gas no convencional, a la espera de la unificación de criterios desde la Unión Europea", que aún no tiene respuesta escrita ${ }^{73}$.

\subsection{Permisos de investigación en el subsuelo marino}

Los permisos denominados Ruedalabola y Tesorillo, ambos en la provincia de Cádiz frente a las costas de Tarifa, fueron otorgados a las empresas norteamericanas Schuepbach Energy España (85\%) y Vancast Exploración, S. L. (15\%) (RD 1771/2010, de 23 de diciembre). Como en otros permisos, existen sospechas de que se extraerá gas de pizarra con técnicas de estimulación porque la empresa se dedica a estas explotaciones en países como EE. UU., Uruguay, Francia, Suiza o Dinamarca. Así que hay bastantes probabilidades de que las investigaciones de Cádiz sean para buscar gas de pizarra o gas en yacimientos de carbón.

Por su parte, el permiso de investigación Géminis (RD 1300/2011, de 16 de septiembre), frente a las costas de Vizcaya, cuyo titular es la empresa Frontera Energy

\footnotetext{
72 Pregunta 184/005524, en BOCG-Congreso, núm. 98-D, de 28 de mayo de 2012, y respuesta en BOCGCongreso, núm. 134-D, de 25 de julio de 2012. No me consta que estos informes que el Gobierno dice haber impulsado se hayan elaborado ya.

${ }^{73}$ Pregunta 184/0088672, en BOCG-Congreso núm. 137-D, de 30 de julio de 2012.
} 
Corporation, S. L., contempla durante el quinto y sexto año de vigencia la "perforación de un sondeo exploratorio, probablemente multilateral, con una profundidad mínima de $2.000 \mathrm{~m}$ ", en lo que parece un indicio de que se utilizarán técnicas de fractura hidráulica. También en la costa vasca resulta especialmente conflictivo el permiso denominado Fulmar, otorgado mediante RD 2120/2008, de 19 de diciembre, a las empresas Repsol (70\%) y SHESA (30\%) y dirigido previsiblemente a sondear las posibilidades de extracción de gas de esquisto en la costa de Vizcaya. Igual que en el permiso Enara, el Gobierno no ha considerado necesario someter a EIA los primeros pozos exploratorios (Fulmar-1 y Pelícano-1) integrados en este permiso.

Aunque todavía se encuentra pendiente de concesión, ha tenido bastante repercusión mediática en la Comunidad Valenciana la solicitud del permiso Polifemo a instancias de la empresa Oil \& Gas Capital (BOE núm. 8, de 10 enero de 2011), que supuestamente explotará gas no convencional en la costa mediterránea, cerca de Gandía. El diario Levante (edición de 18/01/2011) acusa al proyecto de secretismo y dice que la empresa "no quiere desvelar sus intenciones exploratorias". El Grupo Parlamentario Compromís en las Cortes Valencianas, a través de una pregunta con solicitud de respuesta escrita, insta al Gobierno de la Generalitat a pronunciarse sobre la oportunidad del proyecto y a ofrecer toda la información disponible ${ }^{74}$. La empresa insiste en que el objetivo del permiso Polifemo es "el almacenamiento geológico de hidrocarburos y no la extracción de ningún tipo de gas". Un buen ejemplo de la dificultad que entraña conocer exactamente el objeto de los permisos de investigación de hidrocarburos solicitados y/o concedidos en nuestro país.

\subsection{Permisos de investigación de ámbito autonómico}

La Junta de Andalucía ha concedido tres permisos de investigación de hidrocarburos a la empresa Oil \& Gas Capital denominados Ulises 2 y Ulises 3, en la provincia de Jaén (Decreto 86/2012, de 10 de abril) y Penélope en la provincia de Sevilla (Decreto 87/2012, de 10 de abril). Además, el permiso Albero, otorgado a la empresa Storengy

\footnotetext{
74 Pregunta núm. 7628, en BOCV núm. 67, de 17 de abril de 2012. Según el diario Levante (edición de 16/06/2012), el Grupo Parlamentario Socialista en las Cortes Valencianas ha presentado una proposición no de ley en la que emplaza a la cámara a pedir al Gobierno de España que no autorice el permiso POLIFEMO para explorar gas no convencional en el subsuelo de las costas valencianas, al menos hasta que la UE adopte una posición común respecto a la extracción de gas mediante fractura hidráulica. Sin embargo, esta iniciativa no aparece publicada en el BOCV.
} 
España, S. L. pretende evaluar la posibilidad de almacenamiento de gas en cavidades de sal en Cádiz y Sevilla (Decreto 80/2012, de 27 de marzo). Todo parece indicar que los trabajos exploratorios de estos permisos emplearán técnicas de estimulación mediante fractura.

En la Comunidad Autónoma de Cantabria, además de los permisos de Gran Enara que afectan parcialmente a su territorio (Angosto-1 y Usapal), el foco de tensión se centra en el permiso de investigación denominado Arquetu, concedido por Decreto del Consejo de Gobierno de Cantabria 26/2011, de 31 de marzo (BOC núm. 70, de 11 de abril), en favor de la sociedad Trofagás Hidrocarburos, S. L., que es filial de la compañía estadounidense BNK Petroleum Inc., dedicada a la extracción de gas de pizarra (shale gas). Se trata de uno de los pocos permisos de investigación de hidrocarburos concedidos en nuestro país en el que claramente se dice que se realizarán trabajos de "estimulación por fractura". El permiso Arquetu tiene un plazo de vigencia de seis años, durante los cuales se perforarán cuatro pozos en los que se utilizará la fractura hidráulica para comprobar la cantidad y la calidad del gas que albergan las capas de pizarra y decidir si son rentables comercialmente. Se extiende sobre un área de casi 25.000 hectáreas en nueve municipios cántabros, todos pertenecientes a la Mancomunidad de Saja-Nansa, y engloba varios lugares de interés comunitario (LIC) como el río Nansa, el río Saja o la Sierra del Escudo de Cabuérniga, contiguos al Parque Natural de Saja-Besaya.

\section{Ambigüedades de la legislación española vigente}

Una vez conocidos —o intuidos - los principales proyectos de explotación de recursos no convencionales que se desarrollan en nuestro país, me centraré en los problemas jurídicos que se plantean a la luz de la normativa española vigente. En concreto, me referiré a los títulos habilitantes para la investigación y explotación de hidrocarburos mediante fractura hidráulica (2.1) y a sus exigencias ambientales (2.2). 
2.1. Títulos habilitantes: las dificultades para identificar los permisos que emplean fractura hidráulica en España

El régimen para la investigación y el aprovechamiento de hidrocarburos se regula en la $\mathrm{LSHi}^{75}$. En nuestro país, como en la mayoría de Estados europeos, la distinción entre hidrocarburos convencionales y no convencionales no tiene relevancia jurídica. Quiere ello decir que el título habilitante necesario para investigar o explotar yacimientos de hidrocarburos no varía en función del tipo de yacimiento o de la técnica empleada, y tampoco se establece ninguna especialidad procedimental. La competencia para otorgar los permisos de investigación de hidrocarburos corresponde al Estado para aquellos proyectos que afecten al territorio de varias comunidades autónomas o al subsuelo marino, y a las comunidades autónomas para los permisos que se limiten al ámbito territorial de una comunidad autónoma (arts. 3.2.c), 15 y 18.2 LSHi). Ante el creciente número de solicitudes de permisos de investigación de hidrocarburos de los últimos años, lo cierto es que no tenemos criterios claros para identificar las actividades de fractura hidráulica y que, como he dicho antes, debemos deducirlas de simples indicios. La maraña de trámites y licencias exigibles, de ámbito minero, energético y ambiental, haría aconsejable, siguiendo el segundo informe del Parlamento Europeo, la creación de una ventanilla única para estos proyectos ${ }^{76}$.

La falta de información y transparencia en el procedimiento de otorgamiento es uno de los aspectos más criticables del marco jurídico de estos permisos, como denuncia también el Parlamento Europeo ${ }^{77}$. La LSHi regula un trámite de ofertas en competencia que obliga a publicar la solicitud del permiso en el Boletín Oficial del Estado y en el de la comunidad autónoma, "a fin de que en el plazo de dos meses puedan presentarse ofertas en competencia o de que puedan formular oposición quienes se consideren perjudicados en su derecho" (art. 17.2 LSHi). Sin embargo, como no se conoce

\footnotetext{
75 La Ley de Minas de 1973 (LMi), reformada por Ley 54/1980, de 5 de noviembre, clasifica las rocas bituminosas dentro de la sección D), que integra los recursos energéticos. En la década de 1940 el INI impulsó, en el marco del plan de autarquía económica vigente, un proyecto para extraer petróleo de los yacimientos de pizarra bituminosa, pero pronto fue cancelado por su elevado coste de producción. En cualquier caso, la roca bituminosa, a los efectos de la LMi, es un recurso que se extrae con la técnica minera habitual y que posteriormente se somete a un tratamiento para obtener su potencial energético (quema, destilación). Mientras que los hidrocarburos no convencionales objeto del presente estudio se caracterizan por la técnica especial de extracción, basada en la estimulación artificial de la roca (fracking).

${ }^{76}$ PARLAMENTO EUROPEO, "Proyecto de informe sobre aspectos industriales..." cit., p. 7.

${ }^{77}$ Ibid. p. 7.
} 
claramente la índole de los trabajos de investigación ni si se van a utilizar técnicas de fractura hidráulica, la información queda algo descafeinada. Creo que en todos los proyectos relativos a la investigación y/o explotación de yacimientos no convencionales que puedan tener consecuencias graves para el medio ambiente debería ser obligatorio el trámite de audiencia e información pública como parte del procedimiento de autorización. El Parlamento Europeo insta a las empresas explotadoras de yacimientos no convencionales a que faciliten información integral sobre sus actividades, incluida la relativa a los productos químicos que van a emplear en las operaciones de fractura hidráulica. La confidencialidad que protege la LSHi (art. 12 LSHi) no debería estar reñida con la seguridad ni tampoco, desde luego, con los derechos de información ambiental regulados en la normativa europea (Directiva 2003/4/CE) y nacional (Ley 27/2006, de 18 de julio).

\subsection{Requerimientos ambientales: en especial, la evaluación de impacto ambiental}

La avalancha de permisos solicitados y/o concedidos para investigar yacimientos no convencionales en España está generando una creciente opinión pública desfavorable y un movimiento ciudadano, liderado por instituciones, partidos políticos y asociaciones ecologistas, que denuncia las graves afectaciones ambientales y para la salud humana de la técnica de la fractura hidráulica ${ }^{78}$. Aquí, como en tantas otras actividades económicas, se trata de conseguir ese anhelado y razonable equilibrio entre los beneficios económicos de las explotaciones no convencionales y la protección del medio ambiente. En el actual marco jurídico se hace aconsejable, en mi opinión, una moratoria o prohibición temporal de dichas actividades, al menos hasta que las instituciones comunitarias adopten una posición común al respecto y, a la vista de los riesgos potenciales o probados, fijen los requerimientos ambientales exigibles a las explotaciones de recursos no convencionales.

Por lo que respecta a la EIA, el texto refundido de la Ley de Evaluación de Impacto Ambiental aprobado por RD Legislativo 1/2008, de 28 de enero (TRLEIA), en el marco de la Directiva comunitaria, somete a EIA la "extracción de petróleo y gas natural con

78 La plataforma Fracking ez Araba (<frackingezaraba.org/>) y la Asamblea contra la Fractura Hidráulica ( $<$ fracturahidraulicano.info/>) son especialmente activas en sus reivindicaciones y además ofrecen información actualizada sobre los proyectos que se desarrollan en España, las empresas que los promueven y los estudios científicos que se publican sobre el tema. 
fines comerciales, cuando la cantidad extraída sea superior a 500 toneladas por día en el caso del petróleo y de 500.000 metros cúbicos por día en el caso del gas, por concesión" (anexo I, grupo 2, letra d). Estos umbrales, como se ha dicho, son excesivamente elevados para las operaciones de fractura hidráulica, y sería conveniente, o bien rebajar dichos umbrales, o bien incluir la fractura hidráulica en el anexo I independientemente del umbral de producción, como recomienda el primer informe del Parlamento Europeo $^{79}$. En conclusión, los permisos para la investigación de hidrocarburos (convencionales o no) que no alcancen dichos umbrales solo quedarán sometidos a EIA cuando así lo decida el órgano ambiental caso por caso en los supuestos previstos en el artículo 3.2 TRLEIA. Las operaciones que utilizan fractura hidráulica están incluidas en el epígrafe 3 (letras a, b y c) del anexo II del TRLEIA, así que deberán valorarse en atención a las circunstancias del caso concreto.

Desde un punto de vista jurídico, se plantea un problema adicional, y es la fragmentación de los sondeos para eludir el trámite de EIA, como ha sucedido en los permisos Enara, del proyecto Gran Enara, y Fulmar.

En relación con el permiso Enara, inicialmente la empresa titular SHESA remitió al Ministerio de Medio Ambiente la documentación ambiental relativa a dieciséis pozos para explorar hidrocarburos, sondeos Enara-1 a -16, para determinar su sometimiento a EIA. Posteriormente, estos sondeos quedaron reducidos a uno, el denominado Enara-16. Pues bien, el órgano ambiental del Ministerio de Medio Ambiente consideró que los impactos de la perforación de los pozos Enara-16 "son de poca magnitud y complejidad, y de reducida extensión en relación con el área geográfica y la población afectada, por lo que pueden considerarse como no significativos", y resolvió no someter dicho proyecto al procedimiento de $\mathrm{EIA}^{80}$. Llama la atención, por cierto, que en el trámite de consultas ninguna de las asociaciones ecologistas y de defensa de la naturaleza (Ecologistas en Acción, Greenpeace y otras) emitiera informe al respecto. En cuanto a organismos como la Agencia Vasca del Agua, informaron favorablemente por no prever afectaciones al dominio hidráulico que hicieran desaconsejable el sondeo. Poco después, la empresa titular volvió a remitir el proyecto de perforación de un nuevo pozo,

\footnotetext{
${ }^{79}$ PARLAMENTO EUROPEO, “Repercusiones de la extracción de gas...” cit., p. 61.

${ }^{80}$ Resolución de 1 de marzo de 2010, de la Secretaría de Estado de Cambio Climático, sobre la evaluación de impacto ambiental del proyecto Dos pozos para exploración de hidrocarburos, sondeo Enara-16 (BOE núm. 65, de 16 marzo 2010).
} 
denominado Enara-4, para su valoración ambiental. Como en el pozo anterior, tampoco se consideró necesario someter el proyecto a evaluación de impacto ambiental ${ }^{81}$.

La pregunta que inevitablemente hay que plantearse es: ¿por qué no se ha sometido la totalidad del permiso Enara a EIA, tal y como fue otorgado mediante RD 1399/2006? La respuesta es que se ha producido una fragmentación irregular del permiso Enara con el objetivo de evitar el trámite de EIA, presentando de manera individualizada los sondeos como proyectos separados para secuenciar su tramitación y minimizar los impactos. Dicha fragmentación tiene como efecto pernicioso que no permite evaluar el efecto acumulado de todos los sondeos previstos en el programa de investigación del permiso Enara y, por lo tanto, siguiendo a LA CALLE MARCOS, resulta incompatible tanto con el derecho comunitario como con el derecho español, que establece que "la evaluación de impacto ambiental comprenderá la totalidad del proyecto y no sólo las evaluaciones de impacto ambiental parciales de cada fase o parte del proyecto" (art. 5.3 TRLEIA $)^{82}$. Podemos recordar también la doctrina fijada por la Sala de lo ContenciosoAdministrativo del STSJ de Castilla y León núm. 805/2012, de 27 de abril (rec. núm. 2892/2008), estimatoria del recurso interpuesto por una asociación ecologista contra la fragmentación del parque eólico Villabandín II y Ampliación a Villabandín II, en León, que se autorizaron sin tener en cuenta los impactos ambientales del conjunto de los generadores. Adaptando el argumento de la Sala al caso que nos ocupa, podemos concluir también que "no es posible descomponer, a efectos jurídicos, un parque eólico proyectado con estas características para diseccionar de él varios de sus aerogeneradores a los que se daría un tratamiento autónomo" (FJ 4. $\left.{ }^{\circ}\right)$.

\footnotetext{
${ }^{81}$ Resolución de 21 noviembre 2011, de la Secretaría de Estado de Cambio Climático, sobre la evaluación de impacto ambiental del proyecto Perforación de un pozo para exploración de hidrocarburos, sondeo Enara-4, permiso Enara, término municipal de Vitoria-Gasteiz, Araba/Álava (BOE núm. 295, de 8 diciembre 2011). Hago notar la confusa redacción de la Resolución final, de la que parece desprenderse que el proyecto se ha sometido a EIA, si bien establece ciertas medidas protectoras. Más detalles en la base de datos SABIA del Ministerio de Medio Ambiente. Véase también la ponencia "Valoración ambiental de los proyectos de exploración de gas no convencional Gran Enara, en Álava", elaborada por F. OLARREAGA, del Departamento de Medio Ambiente del Gobierno Vasco, y defendida en las Jornadas Técnicas sobre Gas no Convencional (abril 2012). Recuperado el 6 de septiembre de 2012 de $<$ www.jornadasgasvitoria.com>.

82 LA CALLE MARCOS, "Informe sobre la compatibilidad con el Derecho comunitario de la fragmentación en diversos proyectos de las labores correspondientes al permiso de investigación de hidrocarburos ENARA 1614 en las Comunidades Autónomas de Castilla y León y País Vasco", Fundación Nueva Cultura del Agua, 2012, p. 8. Recuperado el 11 de julio de 2012 de $<$ www.fnca.eu/index.php/component/content/article/71-informes/282-informe-fractura-hidraulica $>$.
} 
Por lo que respecta al permiso Fulmar, parece seguir el mismo camino que el anterior. Actualmente se encuentran en fase de información pública los impactos ambientales correspondientes a los sondeos Fulmar-1 y Pelícano-1, fragmentando así el permiso en los distintos pozos que integran los trabajos y sin tener en cuenta las sinergias entre ellos. Este caso ha llegado a conocimiento de las instituciones europeas a través de una pregunta con solicitud de respuesta escrita, formulada a la Comisión por el eurodiputado verde Romeva i Rueda, sobre las prospecciones de gas de esquisto en el mar Cantábrico (E-007627/2011, de 2 de agosto de 2011). En concreto, se trataba de conocer la opinión de la Comisión "respecto de las dos prospecciones que se están realizando en el mar Cantábrico para la obtención de gas de esquisto" y si "se conoce el alcance real del impacto ambiental que dichas prospecciones tendrán en su entorno marítimo". La respuesta escrita del comisario Oettinger (E-007627/2011, de 14 de septiembre de 2011) ponía de manifiesto que "la Comisión tiene conocimiento de que en varios Estados miembros y, entre ellos, en España se están llevando a cabo operaciones de prospección y exploración de gas de esquisto". Muy escuetamente, se limita a recordar que “corresponde a los Estados miembros garantizar, por medio de regímenes adecuados de licencias y autorizaciones, que todas las actividades de prospección y explotación de fuentes de energía se ajusten a los requisitos legales de la UE relativos a la protección de la salud y el medio ambiente, incluso en relación con el agua. En concreto, los proyectos de prospección y explotación de gas de esquisto están regulados por la Directiva de Impacto Ambiental (EIA), que impone a los Estados miembros la responsabilidad de someter ese tipo de proyectos (sean públicos o privados) a evaluación antes de autorizar su ejecución, aplicando, si resulta necesario, el principio de cautela". Y afirma que "la Comisión está reuniendo la información necesaria para tener una visión completa de los efectos y riesgos medioambientales y climáticos que puedan tener los proyectos centrados en el gas de esquisto $\mathrm{y}$, en este contexto, tiene la determinación de garantizar que el marco normativo de la UE siga siendo el adecuado y mantenga un alto nivel de seguridad para el medio ambiente y para las personas".

El Grupo Parlamentario Izquierda Plural ha presentado en el Congreso una proposición no de ley sobre la evaluación de impacto ambiental en los permisos de investigación de hidrocarburos no convencionales concedidos en España que utilizan la técnica de la fractura hidráulica, con el objetivo de "paralizar cualquier avance en perforaciones y sondeos de proyectos de búsqueda de hidrocarburos y someterlos a evaluación de 
impacto ambiental" y "presentar ante esta Cámara durante el próximo periodo de sesiones un Proyecto de Ley de prohibición del uso de la técnica extractiva de la fractura hidráulica" ${ }^{, 83}$.

La gestión de los residuos y la calidad del agua son otros dos requerimientos ambientales de la fractura hidráulica.

El RD 975/2009, de 12 de junio, sobre gestión de los residuos de las industrias extractivas y de protección y rehabilitación del espacio afectado por actividades mineras, se aplica, con condiciones, a la investigación y explotación de hidrocarburos tan solo "en lo referente a las disposiciones relativas a la gestión de los residuos que se derivan de ellas y adaptadas a sus condiciones particulares" (art. 2.1 in fine). En concreto, serán aplicables a estos permisos las normas relativas al plan de gestión de residuos (arts. 16 y 40), que incluye normas relativas al cierre y clausura y que se configura como un contenido obligatorio del plan de investigación (art. 16.2 c) LSHi). Sin embargo, sería conveniente regular algún requisito adicional, ya que es probable, por la novedad de la técnica y el apresuramiento con que se conceden permisos, que las instalaciones de depuración no estén preparadas para tratar residuos de fractura hidráulica. Como recuerda el primer informe del Parlamento Europeo, resulta inaplazable impulsar un documento de referencia sobre las mejores técnicas disponibles en el ámbito de la fractura hidráulica, hasta ahora inexistente ${ }^{84}$.

En cuanto a la utilización del agua necesaria para las operaciones de estimulación, es necesario un estudio hidrogeológico que demuestre la inocuidad de los vertidos en acuíferos y aguas subterráneas previo a la autorización del organismo de cuenca (artículo 102 del texto refundido de la Ley de Aguas, aprobado por RD-Legislativo 1/2011, de 20 de julio, TRLA). A estos efectos, se aconseja reforzar las obligaciones de declaración y los valores límite permitidos de los productos químicos empleados en la fractura hidráulica. Además, el Parlamento Europeo reclama unas normas e inspecciones mínimas de seguridad en la fase de construcción de pozos, que resulta crítica para la calidad de los acuíferos ${ }^{85}$.

\footnotetext{
${ }^{83}$ BOCG-Congreso, núm. 21-D, de 23 de enero de 2012.

${ }^{84}$ PARLAMENTO EUROPEO, "Repercusiones de la extracción de gas...” cit., p. 62.

${ }^{85}$ PARLAMENTO EUROPEO, "Proyecto de informe sobre aspectos industriales..." cit., p. 8.
} 


\section{CONCLUSIONES}

Como he dicho, creo que resulta inaplazable seguir profundizando en el conocimiento de la situación de los yacimientos no convencionales y en la evaluación de sus riesgos (conocidos, potenciales o hipotéticos) promoviendo estudios rigurosos que permitan adaptar, en su caso, la normativa ambiental aplicable a las explotaciones que utilizan fractura hidráulica. En especial, habría que hacer un esfuerzo por homogeneizar la terminología jurídica a nivel comunitario y valorar la conveniencia de regular requisitos distintos para los títulos mineros en función de la técnica de extracción, convencional o no. Hasta ahora resulta muy difícil identificar las operaciones mineras que implican el uso de la fractura hidráulica, como se ha visto en los casos de Francia o de España.

A la vista de estas lagunas e insuficiencias, considero que sería adecuado, aplicando el principio de precaución, que el Gobierno español impulsara una moratoria en la tramitación de nuevos permisos de investigación de hidrocarburos que vayan a utilizar fractura hidráulica, al menos hasta que la Unión Europea adopte una posición común sobre la adaptación del marco normativo aplicable y los riesgos de esta técnica. Recuerdo que el instrumento de la planificación en materia de hidrocarburos permite tener en cuenta criterios de protección ambiental, aunque en este punto solo tenga carácter indicativo (art. $4.3 \mathrm{~h}$ ) LSHi). Para los permisos ya concedidos, habría que extremar la inspección y el control de los trabajos de investigación que se desarrollan, imponiendo modificaciones en los planes de labores si fuera necesario (art. 22 LSHi) y, desde luego, garantizando una adecuada evaluación de los riesgos a través de la EIA y del riguroso cumplimiento de los demás instrumentos de protección ambiental (art. 6 LSHi).

\section{BIBLIOGRAFÍA}

ALONSO SUÁREZ, MINGO GONZÁLEZ, "La expansión de la producción de gas de yacimientos no convencionales (esquistos, capas de carbón y arenas compactas). Una revolución silenciosa", Cuadernos de Energía, núm. 28, 2010, pp. 5-17.

BAMBERGER, OSWALD, "Impacts of Gas Drilling on Human and Animal Health", New Solutions. A Journal of Environmental and Occupational Health Policy, vol. 22, núm. 1, 2012, pp. 51-77. 
BENAVIDES SALAS, "La energía en su laberinto", Cuadernos de Energía, núm. 35, 2012, pp. 11-15.

BILLET, "Le nouveau Code Minier et l'exploitation du gaz de schiste", La Semaine Juridique-Administration et Collectivités Territoriales, núm. 17, 2011, pp. 31ss.

CENTRO DE SOLUCIONES DE ENERGÍA DE DELOITTE y DELOITTE MARKETPOINT LLC, "El impacto económico de las exportaciones de GNL desde EEUU”, Cuadernos de Energía, núm. 35, 2012, pp. 28-43.

DEL GUAYO CASTIELLA, Tratado de Derecho del gas natural, Marcial Pons, Madrid, 2010.

EMBID TELLO, Precaución y Derecho. El caso de los campos electromagnéticos, Iustel, Madrid, 2010.

GRANDOSO, "Fracking. La nueva apuesta de las energías sucias", Revista El Ecologista, núm. 71, 2011. Recuperado el 5 de julio de 2012 de $<$ www.ecologistasenaccion.org $>$.

GOSSEMENT, "Loi sur le gaz de schiste: et maintentant?”, 2011. Recuperado el 12 de julio de 2012 de www.arnaudgossement.com/trackback/3698859.

GOSSEMENT, “Droit minier et droit de l'environnement. Eléments de réflexion pour une réforme relative à l'évaluation environnementale, à l'information et à la participation du public. Rapport remis à Madame Nathalie Kosciusko-Morizet, Ministre de l'Ecologie, du Développement durable, des Transports et du Logement", París, 2011. Recuperado el 4 de julio de 2012 de <www.developpement-durable.gouv.fr/>.

HIDALGO GARCÍA, “Los elementos químicos críticos para las nuevas tecnologías del sector energético", Cuadernos de Energía, núm. 35, 2012, pp. 44-49.

HOWARTH, SANTORO, INGRAFFEA, "Methane and the greenhouse-gas footprint of natural gas from shale formations", Climatic Change Letters, vol. 106, núm. 4, 2011, pp. 679 a 690. Recuperado el 3 de julio de 2012 de $<$ www.springerlink.com/content/0165-0009/106/4/>.

JACKSON, PEARSON, OSBORN, WARNER, VENGOSH, "Research and Policy Recommendations for Hydraulic Fracturing and Shale-Gas Extraction", Center on Global Change, Duke University, Durham, NC, 2011. 
LA CALLE MARCOS, "Informe sobre la compatibilidad con el Derecho comunitario de la fragmentación en diversos proyectos de las labores correspondientes al permiso de investigación de hidrocarburos ENARA 1614 en las Comunidades Autónomas de Castilla y León y País Vasco”, Fundación Nueva Cultura del Agua, 2012. Recuperado el 11 de julio de 2012 de <www.fnca.eu/index.php/component/content/article/71informes/282-informe-fractura-hidraulica>.

LETEURTROIS, "Faut-il interdire l'exploitation des hydrocarbures de schiste en France?", Annales de Mines, núm. 64, 2011.

MATHIEU, "Ressources et reserves mondiales en hydrocarbures non conventionnels", Annales de Mines, núm. 64, 2011.

MATTERN, "Energie-Gewinnung in Polen. Das schmutzige gas”, en Spiegel Online, 2012. Recuperado el 10 de julio de 2012 de <www.spiegel.de/wirtschaft/energiegewinnung-in-polen-das-schmutzige-gas-a-813162.html>.

MARZO, "Recursos convencionales y no convencionales de petróleo y gas", Enseñanza de las Ciencias de la Tierra, núm. 16.3, 2008, pp. 218-228.

MEARNS, "Unconventional Oil and Gas, a Game Changer?", ponencia de la 10." Convención Anual de la Association for the Study of Peak Oil \& Gas (ASPO), Viena, 2012. Recuperado el 23 de julio de 2012 de <www.aspo2012.at/>.

MOONEY, "Los inconvenientes de la fractura hidráulica", Investigación y Ciencia, núm. 424, 2012, pp. 82-87.

MYERS, "Potential Contaminant Pathways from Hydraulically Fractured Shale to Aquifers", Journal of the National Ground Water Association, 2012. Recuperado el 9 de julio de 2012 de www.ngwa.org.

OSBORN, VENGOSH, WARNER, JACKSON, "Methane contamination of drinking water accompanying gas-well drilling and hydraulic fracturing”, en PNAS, Proceedings of the National Academy of Sciences of the United States of America, vol. 108, núm. 20, 2011, pp. 8172-8176. Recuperado el 2 de julio de 2012 de $<$ www.pnas.org/cgi/doi/10.1073/pnas.1100682108>.

SCHULZ, HORSFIELD, KAPP, “Shale Gas: eine unkonventionelle Gasressource für den zukünftigen Energiemix in Europa?”, Bergbau. Zeitschrift für Rohstoffgewinnung, Energie, Umwelt, núm. 6, 2011, pp. 252-256. 
WARNER, JACKSON, DARRAH, OSBORN, DOWN, ZHAO, WHITE y VENGOSH, "Geochemical evidence for possible natural migration of Marcellus Formation brine to shallow aquifers in Pennsylvania", PNAS, Proceedings of the National Academy of Sciences of the United States of America, 2012. Recuperado el 24 de julio de 2012 de $<$ www.pnas.org/cgi/doi/10.1073/pnas.1121181109>.

WOOD, GILBERT, SHARMINA, ANDERSON, FOOTITT, GLYNN, NICHOLLS, "Shale gas: a provisional assessment of climate change and environmental impacts", Tyndall Centre for Climate Change Research, 2011. Recuperado el 2 de julio de 2012 de $\quad<$ www.tyndall.ac.uk/publications/technical-report/2011/shale-gas-provisionalassessment-climate-change-and-environmental $>$.

ZITTEL, "Shale Gas. European Perspectives", ponencia de la 10. 'Convención Anual de la Association for the Study of Peak Oil \& Gas (ASPO), Viena, 2012. Recuperado el 23 de julio de 2012 de <www.aspo2012.at/>. 